\title{
Micromechanical analysis of interfacial transition zone in alkali-activated fly ash-slag
} concrete

\author{
Guohao Fang a,b , Qiang Wang c, Mingzhong Zhang a,* \\ a Department of Civil, Environmental and Geomatic Engineering, University College London, \\ London, WC1E 6BT, UK \\ ${ }^{\mathrm{b}}$ Institute for Advanced Study, Shenzhen University, Shenzhen, 518060, China \\ ${ }^{\mathrm{c}}$ Department of Civil Engineering, Tsinghua University, Beijing, 100084, China
}

Abstract: This paper systematically investigates the micromechanical properties of interfacial transition zone (ITZ) in alkali-activated fly ash-slag (AAFS) concrete using nanoindentation, backscattered electron microscopy and energy dispersive spectroscopy. Results indicate that the micromechanical properties of ITZ depend on the chemical composition of reaction products and its microstructural characteristics. The ITZ with high proportion of N-C-A-S-H and C-A-S-H gels tends to have high elastic modulus because of their superior micromechanical properties. The formation of reaction products would refine the microstructure of ITZ and improve its elastic modulus. The evolution of micromechanical properties of ITZ can be divided into three stages: (i) accelerated growth stage via fast chemical reactions $(<12 \mathrm{~h}$ ); (ii) stationary stage via stable chemical reactions (12 h-7 d); (iii) decrement stage via microcrack propagation (7 d-28 d). ITZ is not the weakest region in AAFS concrete due to its desired micromechanical properties and compact microstructure compared to paste matrix.

Keywords: Alkali-activated materials; Nanoindentation; Elastic modulus; Hardness; Microstructure

\section{Introduction}

Alkali-activated fly ash-slag (AAFS) concrete, as a blended alkali-activated concrete (AAC), is regarded as an eco-friendly alternative to Portland cement (PC) concrete [1, 2]. This new concrete has been attracting increasing attention from industrial engineers and scientific researchers because it can achieve a good synergy between fresh and hardened properties at ambient curing conditions $[\underline{3}$, 4]. It can provide desired workability, mechanical properties and long-term durability in comparison with the sole AAC, such as alkali-activated fly ash (AAF) concrete and alkali-activated slag (AAS) concrete [5-8]. Nevertheless, current demand for AAFS concrete requires a better understanding of its complex microscopic properties $[9,10]$. The interfacial transition zone (ITZ) between aggregate and paste is normally considered to be a key microstructural feature that significantly influences the macroscopic properties of concrete, because it determines the quality of aggregate-paste bond [1113]. Thus, it is vital to explore the microscopic properties of ITZ in order to better understand and tailor the structural performance of AAFS concrete $[\underline{14}, \underline{15}]$.

\footnotetext{
${ }^{*}$ Corresponding author. E-mail address: mingzhong.zhang@ucl.ac.uk (M. Zhang)
} 
In conventional PC concrete, ITZ is commonly regarded as the weakest link between aggregate and paste in terms of mechanical properties and durability $[\underline{11}, \underline{12}, \underline{16}]$. According to the microstructural characterisation, the ITZ in PC concrete has a relatively high porosity compared to the surrounding paste [11], which would directly affect its micromechanical properties [17]. The elastic modulus of ITZ was found to be about $15 \%$ to $30 \%$ lower than that of paste matrix $[13,16]$. In return, the ITZ with relatively low strength and stiffness is prone to cracking as a result of shrinkage or mechanical loading [18], which would facilitate the penetration of aggressive species into concrete and thus reduce the long-term durability of concrete structures [19]. In addition, the ITZ in PC concrete consists of high proportion of calcium hydroxide $(\mathrm{CH})$ crystals and less content of calcium silicate hydrate (C-S-H) gels [20], which would decrease the mechanical properties of PC concrete and lower its resistance to water and ionic penetration but may facilitate the leaching of $\mathrm{CH}$ [21]. Moreover, it was observed that the microstructure and micromechanical properties of ITZ are significantly influenced by the water-to-cement (w/c) ratio [22-24]. Reducing the w/c ratio tends to decrease the porosity of ITZ, leading to a comparable microstructure to paste matrix [22] and would change the influence of ITZ on the overall elastic properties of concrete from negative into positive [23].

The ITZ in AAC seems to play an entirely different role in governing the macroscopic properties of AAC [25-28]. The ITZ in AAF concrete has comparable micromechanical properties to paste matrix, attributing to the dense microstructure formed in this region [21]. This is mainly because of the formation of N-A-S-H gels instead of the $\mathrm{CH}$ crystals formed in PC concrete, which would help to produce a strong bonding between aggregate and paste [25] and contribute to the improvement of mechanical properties of AAF concrete [26]. Additionally, AAS concrete activated by $\mathrm{Na}_{2} \mathrm{SiO}_{3}$ exhibits superior interfacial properties, in which ITZ has low porosity and high strength [27, 29-31]. This can be attributed to the excess $\mathrm{SiO}_{2}$ supplied by the activator, which would promote the formation of C-A-S-H gels with low Ca/Si ratio and refine the porosity of ITZ [29, 32]. Moreover, the ITZ in AAS concrete might have no negative effects on the long-term durability as it would not provide a preferred pathway for the penetration of aggressive species [28].

Although the microscopic properties of ITZ in AAF and AAS concrete have been increasingly investigated, it is worth noting that the studies focusing on microscopic properties of AAFS concrete are extremely rare. To date, most studies only focus on the simple analysis of local morphology of ITZ, which cannot provide direct insight into the microscopic properties of ITZ [33, 34]. Recently, the authors conducted a systematic study of the microstructure evolution of ITZ in AAFS concrete [35], which can be mainly demonstrated as three stages: (i) rapid alkaline reaction with the formation of reaction products $(<12 \mathrm{~h}$ ); (ii) modification of microstructure via products redistribution (12 h-7 d); (iii) reorganisation of microstructure leading to a compact and dense ITZ at $28 \mathrm{~d}$, compared to 
paste matrix. Although the microstructure formation and development of ITZ in AAFS concrete and the relevant mechanisms were discussed in depth in this previous study, the micromechanical properties of ITZ in AAFS concrete and their relation to chemical kinetics and microstructural characteristics have not been extensively explored to date. Characterising the micromechanical properties of ITZ would enable us to build a link between chemistry, microstructure and properties, bringing new insights into the performance of ITZ and the corresponding relationship with macroscopic mechanical properties of AAFS concrete.

The main purpose of this study is to systematically investigate the micromechanical properties of ITZ in AAFS concrete at different curing ages, revealing the microscopic features that affect the macroscopic properties of AAFS concrete. Nanoindentation tests were conducted to measure the micromechanical properties of ITZ including elastic modulus and hardness, while the microstructural features of ITZ were characterised using backscattered electron microscopy (BSEM) and energy dispersive X-ray spectroscopy (EDS). Firstly, the ITZ between aggregate and paste was identified based on the measured micromechanical properties. Afterwards, a series of statistical analysis were performed to explore the evolution of micromechanical properties of ITZ from early age $(3 \mathrm{~h})$ to later age (28 d). Finally, the mechanism of evolution of micromechanical properties of ITZ was discussed in detail from the viewpoints of chemical reactions and microstructure development.

\section{Experimental program}

\subsection{Materials}

The precursors (P) consist of fly ash (FA) and ground granulated blast-furnace slag (GGBS). The chemical composition of FA and GGBS is presented in Table 1 , where the $\left[\mathrm{SiO}_{2}\right] /\left[\mathrm{Al}_{2} \mathrm{O}_{3}\right]$ ratio of FA and the $[\mathrm{CaO}] /\left[\mathrm{SiO}_{2}\right]$ ratio of GGBS are 1.85 and 1.25 , respectively. Fig. 1 shows the particle size distribution of FA and GGBS, where 95\% FA and 92\% GGBS are smaller than $45 \mu \mathrm{m}$ and $40 \mu \mathrm{m}$, respectively. These characteristics can meet the performance criteria for the usage of FA and GGBS for AAFS concrete [36-39]. A combination of sodium hydroxide (SH) with 10 molarity and sodium silicate (SS) with the modulus $\left(\left[\mathrm{SiO}_{2}\right] /\left[\mathrm{Na}_{2} \mathrm{O}\right]\right.$ molar ratio) of 2.0 was used as the alkaline activator (AL), according to the authors' previous research [4]. The modified polycarboxylate-based superplasticizer (SP) $\left(\right.$ Sika $^{\circledR}$ ViscoFlow ${ }^{\circledR} 2000$, Sika, UK) was adopted to adjust the workability of AAFS concrete [3]. The standard sands manufactured based on EN196-1 [40] were selected as fine aggregates, while limestone aggregates with size between $5 \mathrm{~mm}$ and $10 \mathrm{~mm}$ were used as coarse aggregates.

\subsection{Mix proportion}

In this study, the mix proportion of AAFS concrete was selected based on the literature $[\underline{1}, \underline{2}, \underline{5}$, $\underline{6}, \underline{41}, \underline{42}$ ] and the authors' previous research [4] , which can fulfil the requirements of workability [43] setting time [44] and compressive strength [45]. The volume of concrete was set as $1 \mathrm{~m}^{3}$, while the 
content of precursor was set as $400 \mathrm{~kg} / \mathrm{m}^{3}$. Regarding the binder, the FA/GGBS, AL/P, SS/SH and $\mathrm{SP} / \mathrm{P}$ ratios by mass were set as 3, 0.45, 2.0 and 0.01 , respectively. In terms of aggregate, its volume was the surplus volume exclusive of the volume of binder, which was calculated according to the mass and specific density of binder presented in Table 2. The aggregates were mixed by the volume of fine aggregates and coarse aggregates with $35 \%$ and $65 \%$ respectively to achieve an adequate consolidation of concrete [46]. Accordingly, the mix proportion of AAFS concrete was obtained (see Table 3).

\subsection{Sample preparation}

FA, GGBS and aggregates were mixed for $2 \mathrm{~min}$, followed by another 3-min mixing along with the addition of alkaline solution (SH and SS) and SPs. The mixed concrete was cast into the plastic cylinder moulds with $\Phi 25 \times 100 \mathrm{~mm}$, which were put on the vibrating machine. Afterwards, the moulds were sealed by the plastic cover and put in the curing room $\left(20 \pm 2{ }^{\circ} \mathrm{C}, 95 \% \mathrm{RH}\right)$ until testing ages of $3 \mathrm{~h}, 6 \mathrm{~h}, 12 \mathrm{~h}, 1 \mathrm{~d}, 3 \mathrm{~d}, 7 \mathrm{~d}$ and $28 \mathrm{~d}$. At each curing age, a low-speed diamond saw was used to cut the samples into small cylinder specimens with $\Phi 25 \times 3 \mathrm{~mm}$. For the samples at very early ages $(3 \mathrm{~h}$ and $6 \mathrm{~h})$, the freeze-drying method was applied to stop the chemical reactions because it is considered as a promising approach to preserve the microstructure and chemical composition of specimens before fully hardening $[\underline{47}, \underline{48}]$. For the samples at relatively late ages $(12 \mathrm{~h}, 1 \mathrm{~d}, 3 \mathrm{~d}, 7 \mathrm{~d}$ and $28 \mathrm{~d}$ ), the solvent exchange method was used to prevent the chemical reactions through removing the free water inside the hardened specimens [47, 49]. Herein, the isopropanol solution was used as an organic solvent to stop the chemical reaction of testing specimens. The testing samples were then well-polished to provide a flat and smooth surface for the nanoindentation and BSEM tests. An example of the polished specimen is shown in Fig. 2. More details about the sample preparation can be found in the authors' previous study [35].

\subsection{Testing methods}

\subsubsection{Atomic force microscopy test}

The surface topographic of polished specimens was measured using atomic force microscopy (AFM) (Bruker, Dimension ICON, USA) to ensure that the polished samples can fulfil the requirement of nanoindentation test. The specimens were scanned under the Peakforce mode to collect a topographic map. The scanning was operated with an engage setpoint of $0.85 \mathrm{~V}$, a peak force amplitude of $300 \mathrm{mV}$ and a scan rate of $1.0 \mathrm{~Hz}$. The scanning size at the interface was $50 \times 50 \mu \mathrm{m}$. The digital analysis was then conducted on each image to obtain the roughness value. Here, the rootmean-squared roughness number (RMS) was used to describe the surface roughness [50, 51]. The RMS roughness of AAFS samples at different curing ages was calculated and presented in Table 4.

\subsubsection{Nanoindentation test}

Nanoindentation is an effective method to detect the micromechanical properties (e.g. the local 
elastic modulus and hardness) of materials at micro-level [52]. The basic principle of nanoindentation is to measure the mechanical properties of the testing material from the response of the press of a sharp tip [52]. Fig. 3 shows a typical load-depth curve that starts with a constantly increasing loading, followed by a constant holding and a constantly decreasing loading [51]. According to the initial slope of the elastic unloading curve, two mechanical properties including indentation modulus $(M)$ and hardness $(H)$ can be obtained as follows $[\underline{53}, \underline{54}]$ :

$M=\frac{1}{2}\left(\frac{d p}{d h} \sqrt{\frac{\pi}{A}}\right) \mid h=h_{\max }$

$H=\frac{P_{\max }}{A}$

where $p$ is the indentation load, $p_{\max }$ is the maximum indentation load, $h$ is the indentation depth, $h_{\max }$ is the maximum indentation depth, and $A$ is the projected area of the elastic contact.

The indentation modulus $(M)$ is associated with the elastic properties of the testing material $(E)$ and the indenter tip $\left(E_{t i p}\right)$ as [55]:

$\frac{1}{M}=\frac{1-v^{2}}{E}+\frac{1-v_{t i p}^{2}}{E_{t i p}}$

where $v$ is the Poisson's ratio of the testing material, and $v_{\text {tip }}$ is the Poisson's ratio of the indenter tip.

For the diamond indenter used in this study, the values of $E_{\text {tip }}$ and $v_{\text {tip }}$ are $1140 \mathrm{GPa}$ and 0.07 , respectively. For AAC, the value of Poisson's ratio $(v)$ is in the range of 0.13 and 0.26 [56, 57]. Since the change of $v$ from 0.13 to 0.26 would not significantly affect the results according to Eq. (3), the suggested $v$ for the testing material was set as 0.2 in this study. Accordingly, the elastic modulus $(E)$ can be calculated as [됴]:

$E=\left(1-v^{2}\right) \times\left[\frac{1}{M}-\frac{\left(1-v_{t i p}^{2}\right)}{E_{t i p}}\right]^{-1}$

The nanoindentation instrument with a Berkovich indenter tip (BRUKER, Hysitron TI 950, Germany) was used in this study, which can achieve a load resolution of $1 \mathrm{nN}$ and a displacement resolution of $0.04 \mathrm{~nm}$. Nanoindentation test started with the loading at a constant increasing rate of $400 \mu \mathrm{N} / \mathrm{s}$ until it reached the maximum load of $2 \mathrm{mN}$. Afterwards, the load was held for $2 \mathrm{~s}$ followed by the unloading at a similar constant rate. The maximum load of $2 \mathrm{mN}$ corresponded to the average indentation depth of $350 \mathrm{~nm}$. The average indentation depth $(350 \mathrm{~nm})$ was more than 2 times greater than the RMS roughness of testing samples, suggesting the effect of roughness on the measured properties was effectively avoided (see Table 4).

As shown in Fig. 4, the grid nanoindentation area covered the dimension of $50 \times 100 \mu \mathrm{m}$ across the interface between aggregate and paste matrix. The space between the indented points was set as $10 \mu \mathrm{m}$ and $5 \mu \mathrm{m}$ in the lateral and vertical directions, which was 28 times and 14 times more than the indentation depth, respectively. Such distance should be sufficient to avoid the effects of interacting microvolume during nanoindentation tests, which is normally about 3-5 times the indentation depth 
[59]. In total, 126 nanoindentation points for each sample were taken for the statistical analysis.

\subsubsection{BSEM-EDS test}

A field emission scanning electron microscopic (ZEISS, GeminiSEM, Germany) equipped with BSEM and EDS was used to characterise the microstructural and chemical features of ITZ. Before testing, a layer of carbon was coated on the surface of sample under vacuum in order to improve the conductivity of testing sample. BSEM tests were performed at $10 \mathrm{kV}$ voltages under the working distance of $8.9 \mathrm{~mm}$. The BSEM images with a pixel size of $0.25 \mu \mathrm{m}$ were captured at a magnification of $500 \times$. For EDS analysis, the "line mode" was used in this study, where the line scanning was performed with a dwell time of $5 \mathrm{~ms}$ at 500 testing points.

\section{Results}

\subsection{Micromechanical properties}

\subsubsection{Nanoindentation data analysis}

Fig. 5 shows the results of grid nanoindentation test on AAFS concrete. The area near the edge of coarse aggregate with $100 \times 50 \mu \mathrm{m}$ was chosen for nanoindentation test (Fig. 5a). Here, the AAFS sample at $6 \mathrm{~h}$ of curing was used as an example. Fig. $5 \mathrm{~b}$ depicts the load-depth curves of the testing points along a testing line from aggregate to paste matrix. Three different regions including aggregate, ITZ and paste matrix can be well distinguished, where the differences in the indentation depth and the slope of unloading portion among these curves can be clearly recognized. This can be attributed to the differences in hardness and stiffness among the corresponding material phases. The indentation depth is associated with the hardness, while the slope of unloading portion is related to the elastic modulus. The order of indentation depth among these regions is aggregate $<$ ITZ $<$ paste matrix, while the order of slope is aggregate $>$ ITZ $>$ paste matrix. This suggests that aggregate has the highest hardness and highest elastic modulus, followed by ITZ and paste matrix.

As seen in Fig. 5c and 5d, the elastic modulus and hardness were calculated and plotted in a twodimensional contour map according to the load-depth curves. Taking the contour map of elastic modulus as an example, the red area represents the hard matrix with higher elastic modulus, while the blue area stands for the soft matrix with lower elastic modulus. Combined with the analysis of microscopy image (Fig. 5a) and load-depth curves (Fig. 5b), the contour map can be divided into three categories, i.e., aggregate, ITZ and paste matrix (Fig. 5c). The aggregate covers the colour from green to red due to its relatively high elastic modulus, while the paste matrix with relatively low elastic modulus is presented as blue. The area with median value is correlated to ITZ, which covers the colour from light blue to light green. Similar results can also be found in the contour map of hardness (Fig. 5d).

\subsubsection{Micromechanical properties of ITZ}

The characterisation of micromechanical properties of ITZ and paste matrix was performed based 
on a series of statistical analysis, where 126 indentations given on a grid of $50 \times 100 \mu \mathrm{m}$ in each sample were analysed. In the analysis, the micromechanical properties including elastic modulus and hardness were obtained from 20 strips with $5-\mu \mathrm{m}$ width. To estimate the variation of elastic modulus and hardness against the distance from the aggregate surface, the mean values of these properties were calculated using 6 grid points in each strip. Additionally, the elastic modulus and hardness were plotted in the counter map to visualize the phase distribution in the testing area. Fig. 6 shows the mean values of elastic modulus and hardness against the distance from aggregate and the counter maps of elastic modulus and hardness at different curing ages. It should be noted that the elastic modulus was mainly discussed in the following sections considering the similar trend between curves of elastic modulus and hardness.

As seen in Fig. 6a, the elastic modulus is generally reduced by increasing the distance from aggregate at $3 \mathrm{~h}$. Aggregate has the highest elastic modulus ( $>30 \mathrm{GPa}$ ), followed by ITZ and paste matrix, whose elastic moduli are in the range of 10-20 GPa and 0-10 GPa, respectively. A similar trend of elastic modulus can be observed at $6 \mathrm{~h}$ and $12 \mathrm{~h}$ (Fig. $6 \mathrm{~b}$ and 6c), where the elastic modulus of different regions follows an order of aggregate $(>30 \mathrm{GPa})>\operatorname{ITZ}(10-30 \mathrm{GPa})>$ paste matrix $(0$ $20 \mathrm{GPa}$ ). Between $1 \mathrm{~d}$ and $3 \mathrm{~d}$, the elastic modulus of ITZ is stable at 10-30 GPa (Fig. 6d and 6e), while the elastic modulus of paste matrix increases from 0-20 GPa to 10-30 GPa at $1 \mathrm{~d}$ and then decreases to $0-10 \mathrm{GPa}$ at $3 \mathrm{~d}$. As the curing age increases from $7 \mathrm{~d}$ to $28 \mathrm{~d}$, the elastic moduli of ITZ and paste matrix become close to each other and have a similar value of 10-20 GPa (Fig. 6f and 6g).

Fig. 7 shows the mean values of elastic modulus and hardness in ITZ and paste matrix of AAFS concrete at different curing ages. As seen in Fig. 7a, the elastic modulus of ITZ is $13.58 \mathrm{GPa}$ at $3 \mathrm{~h}$, which is higher than that of paste matrix, i.e. $5.11 \mathrm{GPa}$. With the increase of curing age from $3 \mathrm{~h}$ to $12 \mathrm{~h}$, the elastic modulus of ITZ tends to be much higher than that of paste matrix and increases significantly from $13.58 \mathrm{GPa}$ to $21.21 \mathrm{GPa}$, while the elastic modulus of paste matrix is stable at around $5 \mathrm{GPa}$. At $1 \mathrm{~d}$, the elastic modulus of ITZ is slightly decreased to $18.37 \mathrm{GPa}$, while that of paste matrix approaches $19.59 \mathrm{GPa}$, implying that ITZ and paste matrix have a similar elastic modulus. Afterwards, the elastic modulus of paste matrix reduces obviously to $11.33 \mathrm{GPa}$ at $3 \mathrm{~d}$, making it lower than the elastic modulus of ITZ again. With increasing curing age from $3 \mathrm{~d}$ to $28 \mathrm{~d}$, the elastic modulus of ITZ is decreased steadily from $18.5 \mathrm{GPa}$ to $13.20 \mathrm{GPa}$, while that of paste matrix is increased slightly from $11.33 \mathrm{GPa}$ to $13 \mathrm{GPa}$, leading to a similar elastic modulus of these two regions at $28 \mathrm{~d}$. A similar trend can also be observed in the evolution of hardness, as shown in Fig. $7 \mathrm{~b}$.

\subsubsection{Micromechanical properties of reaction products in ITZ}

It is known that reaction products are the main components in ITZ, which would directly affect the micromechanical properties of ITZ [35]. Thus, the micromechanical properties of reaction products were analysed to investigate the mechanism behind the development of micromechanical 
properties of ITZ. Gaussian deconvolution method is commonly used to characterise the clusters of experimental data with distinct mechanical properties, which can be divided into three steps including experimental fitting, phases identification and data quantification [60]. In the first step, as shown in Fig. 8, the frequency density of elastic modulus (normalised histogram with a bin size of $2.5 \mathrm{GPa}$ ) was fit by three Gaussian distribution functions using the statistical analysis software called PeakFit [61, 62]. Normally, five Gaussian distribution curves representing the five solid phases including three types of reaction products (N-A-S-H, N-C-A-S-H and C-A-S-H gels) and two types of unreacted particles (fly ash and slag) are considered in the Gaussian deconvolution [63]. After that, different phases with different elastic modulus were identified according to the literature [64-66] and the authors' previous research [63]. The elastic modulus of reaction products is lower than $50 \mathrm{GPa}$ while that of unreacted particles is generally higher than $50 \mathrm{GPa}$. Therefore, the three deconvoluted phases with elastic modulus of lower than $35 \mathrm{GPa}$ are associated with the existence of three types of reaction products, following the order of N-A-S-H $<$ N-C-A-S-H $<$ C-A-S-H [63] (Fig. 8). The first peak was assigned to the N-A-S-H gels with elastic modulus of around $10 \mathrm{GPa}$, while the second and third peaks were corresponding to the N-C-A-S-H gels $(\sim 20 \mathrm{GPa})$ and C-A-S-H gels $(\sim 30 \mathrm{GPa})$, respectively. The threshold value defining the frontier between N-A-S-H gels and N-C-A-S-H gels was set as the point of intersection between Gauss 1 (N-A-S-H gels) and Gauss 2 (N-C-A-S-H gels). Similarity, the intersection between Gauss 2 (N-C-A-S-H gels) and Gauss 3 (C-A-S-H gels) was considered as the threshold value to determine the boundary between N-C-A-S-H and C-A-S-H gels. Accordingly, the threshold values of $15 \mathrm{GPa}$ and $26 \mathrm{GPa}$ were used to distinguish N-A-S-H, N-C-AS-H and C-A-S-H gels in terms of elastic modulus (Fig. 8). The determination of threshold value should be slightly adjusted for different samples as it varies from sample to sample. Finally, the mean value and volume fraction of each phase can be statistically characterised based on the total frequency density within each threshold value. It is worth noting that the frequency of occurrence in the solid phase was used to quantify the volume fraction, as the elastic modulus of gas phase $(<0.1 \mathrm{GPa})$ was not considered in the decovlution process.

As shown in Fig. 9, the cluster allocation and volume fractions of different reaction products in ITZ and paste matrix at different ages were successfully characterised. At early ages ( $3 \mathrm{~h}-12 \mathrm{~h})$, the volume fraction of N-A-S-H gels in ITZ is much lower than that in paste matrix, while the volume fractions of N-C-A-S-H gels and C-A-S-H gels are obviously higher than those in paste matrix (Fig. $9 \mathrm{a}-\mathrm{c})$. At $1 \mathrm{~d}$, the volume fraction of N-A-S-H gels in ITZ becomes higher than that in paste matrix, but the volume fractions of N-C-A-S-H gels and C-A-S-H gels are lower than those in paste matrix at this stage (Fig. 9d). At later curing ages (1 d-28 d), the volume fractions of all types of reaction products in ITZ become close to those in paste matrix (Fig. 9e-g).

Fig. 10 shows the change in volume fractions of different reaction products in ITZ and paste 
matrix. This information would be helpful for understanding the effects of reaction products on the development of elastic modulus of ITZ and paste matrix. Regarding the ITZ (Fig. 10a), it can be observed that the volume fraction of N-A-S-H gels is generally higher than that of N-C-A-S-H gels and C-A-S-H gels, regardless of curing age. Nevertheless, the volume fraction of each reaction product varies with the increase of curing age. For N-A-S-H gels, the volume fraction decreases significantly from $67.44 \%$ to $30 \%$ at early $6 \mathrm{~h}$, but increases steadily between $6 \mathrm{~h}$ and $1 \mathrm{~d}$, reaching $60 \%$ at $1 \mathrm{~d}$. Afterwards, it decreases to $43.75 \%$ at $3 \mathrm{~d}$, but increases again at later curing age and finally reaches $68.52 \%$ at $28 \mathrm{~d}$. In contrast, the volume fraction of N-C-A-S-H gels increases significantly from $25.58 \%$ to $43.33 \%$ between $3 \mathrm{~h}$ and $6 \mathrm{~h}$ and then decreases steadily to $24 \%$ at $1 \mathrm{~d}$. Subsequently, it increases to $40.62 \%$ at $3 \mathrm{~d}$, followed by a decrease between $3 \mathrm{~d}$ and $28 \mathrm{~d}$, reaching $27.78 \%$ at $28 \mathrm{~d}$. The developing trend in volume fraction of C-A-S-H gels is similar to that of N-C-A-S-H gels, which is increased from $6.98 \%$ to $26.67 \%$ at early $6 \mathrm{~h}$, followed by a steady decrease from $26.67 \%$ to $16 \%$ as the curing age increases from $6 \mathrm{~h}$ to $3 \mathrm{~d}$. Afterwards, it increases to $48.27 \%$ at $7 \mathrm{~d}$, but then decreases dramatically to $3.7 \%$ at $28 \mathrm{~d}$.

Regarding the paste matrix (Fig. 10b), it can also be observed that the N-A-S-H gels dominate the volume fraction of reaction products, regardless of curing ages. However, the evolution process of reaction products in this region is less complicated compared to that in ITZ. At early curing ages (3 $\mathrm{h}-12 \mathrm{~h}$ ), the volume fractions of all reaction products are stable. The volume fraction of N-A-S-H gels is stable at around $90 \%$, while the volume fractions of N-C-A-S-H gels and C-A-S-H gels are stable at around $6 \%$ and $4 \%$, respectively. At $1 \mathrm{~d}$, the volume fraction of $\mathrm{N}-\mathrm{A}-\mathrm{S}-\mathrm{H}$ gels is decreased dramatically to $36.36 \%$, while the volume fractions of $\mathrm{N}-\mathrm{C}-\mathrm{A}-\mathrm{S}-\mathrm{H}$ gels and C-A-S-H gels are increased significantly to $45.45 \%$ and $18.19 \%$, respectively. Afterwards, the volume fractions of all reaction products become relatively stable at later curing ages ( $3 \mathrm{~d}-28 \mathrm{~d})$. At $28 \mathrm{~d}$, the volume fractions of N-A-S-H gels, N-C-A-S-H gels and C-A-S-H gels reach 55\%, 35\% and 10\%, respectively.

\subsection{Microstructural characteristics}

\subsubsection{Morphology of ITZ}

Fig. 11a shows the morphology of interface between aggregate and paste at $3 \mathrm{~h}$. The morphology can be divided into different phases based on the Gaussian deconvolution method, where the greyscale histogram of image was deconvolved into different Gaussian curves by using a statistical analysis software called PeakFit [35]. It can be seen from Fig. 11b that three different phases including uncreated particles, reaction products and pores can be identified and labelled in different colours. The unreacted particles are labelled in red, while the reaction products are presented as light blue and the pores are labelled in blue. Here, the ITZ is marked based on the results of nanoindentation test, where the region with different micromechanical properties in comparison with paste matrix is considered as ITZ (Fig. 6). It can be observed that ITZ and paste matrix have different microstructural 
features. Regarding the distribution of unreacted particles, the size and density of unreacted particles in ITZ are smaller than that in paste matrix, which would lead to a relatively high local AL/P ratio in ITZ (Fig. 11c). In terms of reaction products, more reaction products are accumulated in the area adjacent to aggregate than the area far away from aggregate (Fig. 11d). Regarding the pore structure, the porosity of ITZ is smaller than that of paste matrix, as shown in Fig. 11e. In addition, some initial microcracks can be found in both ITZ and paste matrix.

\subsubsection{Evolution of pore structure in ITZ}

Since the pore structure is a key microstructural characteristic that would directly affect the micromechanical properties of ITZ, the evolution of pore structure was further analysed in this study. An open-source image analysis software Fiji was used to characterise the pore size distribution (PSD) and porosity of ITZ [67]. Since the size of single pores (typically $<0.1 \mu \mathrm{m}$ ) is smaller than the pixel size of BSEM images $(0.25 \mu \mathrm{m})$, the characterised pores are related to the porous patches instead of the singles pores. Thus, only the pores (i.e. porous patches including capillary pores, cracks and hollow reaction shells) with size higher than $0.25 \mu \mathrm{m}$ can be quantified in this study.

Fig. 12 shows the PSD and volume fraction of porosity of ITZ at different curing ages. The PSD spectra of ITZ shown in Fig. 12a reveals several important features of pore structure. First, the pores with size between $0.25 \mu \mathrm{m}$ and $2.5 \mu \mathrm{m}$ dominate the pores in ITZ, followed by the pores with size of 2.5-5 $\mu \mathrm{m}$ and the pores with size larger than $5 \mu \mathrm{m}$, regardless of curing ages. Second, the PSD intensity is decreased steadily at early ages ( $3 \mathrm{~h}-3 \mathrm{~d})$, followed by an increase at later ages ( $3 \mathrm{~d}-28 \mathrm{~d})$. More specifically, as seen in Fig. 12b, the overall porosity of ITZ is reduced continuously from 1.61\% to $0.25 \%$ at early $3 \mathrm{~d}$, followed by a slight increase from $0.25 \%$ to $0.45 \%$ between $3 \mathrm{~d}$ and $28 \mathrm{~d}$. In addition, it can be observed that the percentage of pores with size of 0.25-2.5 $\mu \mathrm{m}$ decreases steadily from $82.50 \%$ to $70.66 \%$ between $3 \mathrm{~h}$ and $3 \mathrm{~d}$, and then increases dramatically to $97.52 \%$ at $28 \mathrm{~d}$. In contrast, the percentages of the pores with other sizes $(2.5-5 \mu \mathrm{m}$ and $>5 \mu \mathrm{m})$ increase at early $3 \mathrm{~d}$, but decrease between $3 \mathrm{~d}$ and $28 \mathrm{~d}$. Regarding the paste matrix, it can be seen from Fig. 13a that the overall changing trend of pore structure in paste matrix is similar to that in ITZ. However, the PSD density of paste matrix is higher than that of ITZ, especially at early $12 \mathrm{~h}$. As seen in Fig. 13b, the porosity of paste matrix is between $4.17 \%$ and $6.16 \%$ at early $12 \mathrm{~h}$, which is obviously higher than that of ITZ, i.e. $0.76-1.61 \%$. Afterwards, the porosity of paste matrix is decreased significantly to $1.14 \%$ at $1 \mathrm{~d}$, followed by a steady decrease to $0.67 \%$ at $7 \mathrm{~d}$ and an increase to $1.21 \%$ at $28 \mathrm{~d}$.

The continuous decrease of porosity at early ages regardless of ITZ or paste matrix can be attributed to the alkaline reaction that would generate reaction products to fill capillary pores. The increase of porosity at later curing ages can be related to the microcracking occurred in ITZ and paste matrix. As shown in Fig. 14, the microcracks are changed obviously with the increase of curing ages. It can be seen from Fig. 14a-b that some initial microcracks exist in both ITZ and paste matrix, which 
might be caused by the early-age shrinkage, e.g., plastic shrinkage and autogenous shrinkage. In addition, the freeze-drying method used to stop chemical reactions for the samples at $3 \mathrm{~h}$ and $6 \mathrm{~h}$ might also lead to the formation of initial microcracks. Nevertheless, the microcracks become less and finer with the continuous curing from $6 \mathrm{~h}$ to $1 \mathrm{~d}$ regardless of ITZ or paste matrix due to the formation of reaction products (Fig. 14b-d). Afterwards, some microcracks induced by later-age shrinkage (e.g. dry shrinkage) can be observed in paste matrix, which further propagate to ITZ with the increase of curing ages from $3 \mathrm{~d}$ to $28 \mathrm{~d}$ (see the yellow circles in Fig. 14e-g).

\subsection{Chemical features}

Fig. 15 shows the distribution of elements across the interface from the surface of limestone aggregate to the edge of paste at different curing ages, where four key elements including silicon ( $\mathrm{Si}$ ), calcium $(\mathrm{Ca})$, aluminium $(\mathrm{Al})$ and sodium $(\mathrm{Na})$ are presented. Apparently, the concentration of $\mathrm{Ca}$ is stable at a high level in the region of aggregate due to the high content of $\mathrm{Ca}$ that limestone aggregate contains. The concentrations of $\mathrm{Si}, \mathrm{Al}$ and $\mathrm{Na}$ are stable at a low level in the region of aggregate but changes sharply at the aggregate-paste boundary. Given that the small amount of Na presented in FA and GGBS (Table 1), the increase of $\mathrm{Na}$ in the paste region might indicate the formation of reaction products (e.g. N-A-S-H and N-C-A-S-H gels) under the activation of Na-rich alkaline activator (SS $+\mathrm{SH})$. The high concentrations of $\mathrm{Si}$ and $\mathrm{Al}$ can also be found in this region, confirming the formation of reaction products as well. As seen in Fig. 15a-c, the concentrations of Si, Al and Na in ITZ are higher than that in paste matrix between $3 \mathrm{~h}$ and $12 \mathrm{~h}$, implying the formation of more reaction products in ITZ. Afterwards, the concentrations of these elements in ITZ become close to those in paste matrix between $1 \mathrm{~d}$ and $28 \mathrm{~d}$ (Fig. 15d-g), indicating a similar reaction rate in ITZ and paste matrix at later curing ages ( $1 \mathrm{~d}-28 \mathrm{~d})$.

\section{Discussion}

The combination of nanoindentation, BSEM and EDS test results indicates that the micromechanical properties of ITZ in AAFS concrete are determined by two factors: (i) the chemical composition of reaction products, and (ii) the microstructural characteristics. In the following subsections, the effects of these two factors on the micromechanical properties of ITZ are discussed in detail. In addition, a comparison between micromechanical properties of ITZ and paste matrix is also discussed to further understand the role of ITZ in AAFS concrete.

\subsection{Effect of chemical composition of reaction products}

Previous studies have reported that different reaction products have different micromechanical properties $[\underline{63}, \underline{66}, \underline{68}]$. The elastic modulus of reactions products in AAFS follows an order of N-AS-H gels $<$ N-C-A-S-H gels $<$ C-A-S-H gels, which can be attributed to their different level of structure disorder and gel porosity [63]. This implies that the chemical composition of reaction products in ITZ would determine its micromechanical properties. 
Fig. 16 shows the evolution of elastic modulus and volume fraction of reaction products in ITZ. During the early curing ages ( $3 \mathrm{~h}-12 \mathrm{~h})$, the elastic modulus of ITZ is increased significantly from 13.58 GPa to 21.21 GPa. This can be ascribed to the increase in volume fractions of N-C-A-S-H gels and C-A-S-H gels from $25.58 \%$ to $38.1 \%$ and from $6.98 \%$ to $23.8 \%$, respectively, which have relatively high elastic moduli. The increase in volume fractions of N-C-A-S-H gels and C-A-S-H gels is a result of the quick dissolution of Ca from GGBS due to its high reactivity [69-71].

At $1 \mathrm{~d}$, the elastic modulus of ITZ is decreased from $21.21 \mathrm{GPa}$ to $18.37 \mathrm{GPa}$, which is related to the decrease in volume fractions of N-C-A-S-H gels and C-A-S-H gels from $38.1 \%$ to $24 \%$ and from $23.8 \%$ to $16 \%$, respectively due to the reduction of free Ca releasing from GGBS, implying that GGBS in ITZ has been almost completely dissolved [72-74]. This can be ascribed to the low content of GGBS that occupies $25 \%$ of the total precursors for AAFS concrete. In comparison, more $\mathrm{Al}$ and Si can be supplied from the continuous dissolution of FA due to its high content $(75 \%$ of the total precursors), contributing to the increase in volume fraction of N-A-S-H gels from $38.1 \%$ to $60 \%$.

Between $1 \mathrm{~d}$ and $3 \mathrm{~d}$, the elastic modulus of ITZ becomes stable at around $18.5 \mathrm{GPa}$, which is associated with the stable chemical reaction at this stage. During this period, the volume fraction of $\mathrm{N}-\mathrm{A}-\mathrm{S}-\mathrm{H}$ gels is decreased from $60 \%$ to $43.75 \%$, while the volume fraction of N-C-A-S-H gels is increased significantly from $24 \%$ to $40.62 \%$ and that of C-A-S-H gels remains stable at around $16 \%$. This suggests that part of N-A-S-H gels have been transformed into N-C-A-S-H via interchanging between $\mathrm{Ca}$ and $\mathrm{Na}$. Since $\mathrm{Ca}$ has a higher polarising power than $\mathrm{Na}$, the Na within N-A-S-H gels would be replaced by $\mathrm{Ca}$ [75]. Given that GGBS in ITZ has been almost completely dissolved at $1 \mathrm{~d}$, the mobile $\mathrm{Ca}$ in ITZ might be released from the paste matrix due to the concentration gradient between these two regions [35].

With the increase of curing age from $3 \mathrm{~d}$ to $7 \mathrm{~d}$, the elastic modulus is declined slightly from 18.5 $\mathrm{GPa}$ to $17.68 \mathrm{GPa}$, attributing to the transformation between different reaction products. During this period, the volume fraction of N-A-S-H gels is increased slightly from $43.75 \%$ to $48.27 \%$, which indicates that the effects of $\mathrm{Ca}$ on N-A-S-H gels become less sensitive to the decrease of mobile Ca. The volume fraction of N-C-A-S-H gels is declined from $40.62 \%$ to $24.14 \%$, while that of C-A-S-H gels is increased from $15.63 \%$ to $27.59 \%$, implying the transformation between N-C-A-S-H gels and C-A-S-H gels, where $\mathrm{Na}$ in N-C-A-S-H gels is continually replaced by $\mathrm{Ca}$ and eventually leading to the formation of C-A-S-H gels [75].

At $28 \mathrm{~d}$, a sharp decrease of elastic modulus from $17.68 \mathrm{GPa}$ to $13.2 \mathrm{GPa}$ can be observed, which can be explained by the significant increase in volume fraction of N-A-S-H gels with relatively low elastic modulus and the obvious decrease in volume fraction of C-A-S-H gels. In detail: the volume fraction of N-A-S-H gels is increased significantly from $48.27 \%$ to $68.52 \%$, while the volume fraction of C-A-S-H gels is decreased dramatically from $27.59 \%$ to $3.7 \%$. This can be ascribed to the reduction 
of free Ca releasing from GGBS, indicating that GGBS in both ITZ and paste matrix has been almost fully dissolved.

According to the discussion above, the evolution of micromechanical properties of ITZ can be divided into three stages: (i) accelerated growth stage ( $<12 \mathrm{~h}$ ), (ii) stationary stage (12 h-7 d), and (iii) decrement stage ( $7 \mathrm{~d}-28 \mathrm{~d})$. This finding is consistent with the microstructure evolution of ITZ, as discussed in the authors' previous study [35].

\subsection{Effect of microstructural characteristics}

It is known that the pores and microcracks are two key microstructural features, which would directly affect the micromechanical properties of ITZ [18, 76]. As shown in Fig. 12, the total porosity of ITZ is decreased dramatically from $1.61 \%$ to $0.76 \%$ at early ages $(<12 \mathrm{~h})$ due to the rapid chemical reactions occurred in this region, which would promote the formation of reaction products and refine the pore structure. Meanwhile, the initial microcracks are refined (Fig. 14a-c). As a result, the microstructure of ITZ becomes compact, leading to an obvious improvement in its micromechanical properties, from $13.58 \mathrm{GPa}$ to $21.21 \mathrm{GPa}$ (Fig. 14). Between $1 \mathrm{~d}$ and $7 \mathrm{~d}$, the porosity of ITZ is stable at a relatively low level between $0.25 \%$ and $0.42 \%$ (Fig. 12), which is corresponding to its stable elastic modulus with around $18 \mathrm{GPa}$ during this period (Fig. 16). With the increase of curing age from $7 \mathrm{~d}$ to $28 \mathrm{~d}$, the microstructure of ITZ becomes less dense, accompanied by an increase in porosity from $0.36 \%$ to $0.45 \%$ (Fig. 12) and the microcracking occurred in this region (Fig. 14g). The appearance of microcracks in ITZ would significantly reduce the bond between solid phases and lead to the occurrence of micro gaps within the testing area itself. This would decrease the confinement of the surrounding matrix in the indented region and consequently result in a relatively low elastic modulus of ITZ (Fig. 16). These findings indicate that the formation of reaction products would help reduce the pore size, refine the microstructure and consequently enhance the micromechanical properties of ITZ, especially at early ages $(<12 \mathrm{~h})$. However, the microcracking induced by shrinkage may inversely affect the microstructure of ITZ and reduce its micromechanical properties at later curing ages $(>7 \mathrm{~d})$.

\subsection{Comparison between micromechanical properties of ITZ and paste matrix}

The relative micromechanical properties between ITZ and paste matrix play a significant role in the overall stress-strain relationship and failure patterns of concrete [77]. Therefore, it is vital to make a direct comparison between the micromechanical properties of ITZ and paste matrix in order to further understand the effects of ITZ on the overall performance of AAFS concrete.

Fig. 17 shows a comparison between the elastic moduli of ITZ and paste matrix of AAFS concrete at different curing ages. Within the first $12 \mathrm{~h}$, the elastic modulus of ITZ (13.58-21.21 GPa) is obviously higher than that of paste matrix (4.32-7.45 GPa), which can be attributed to the continuous chemical reactions occurred in ITZ due to the relatively high AL/P ratio in ITZ. The accelerated 
chemical reactions in ITZ would promote the formation of reaction products, resulting in a compact microstructure and a high elastic modulus in this region. This result shows a good agreement with the analysis of pore structure (Figs. 12 and 13 ) that the porosity of ITZ $(0.76 \%-1.61 \%)$ is obviously lower than that of paste matrix $(4.17 \%-6.16 \%)$ during this period. In addition, the accelerated chemical reactions facilitate the formation of N-C-A-S-H gels and C-A-S-H gels in ITZ. As seen in Fig. 9a-c, the volume fractions of N-C-A-S-H gels and C-A-S-H gels in ITZ are higher than that in paste matrix, resulting in a high elastic modulus of ITZ.

At $1 \mathrm{~d}$, the elastic modulus of ITZ $(18.37 \mathrm{GPa})$ is close to that of paste matrix $(19.59 \mathrm{GPa})$, which can be ascribed to the formation of more reaction products with high elastic modulus in paste matrix. The volume fractions of N-C-A-S-H gels and C-A-S-H gels in paste matrix become higher than those in ITZ (Fig. 9d) as the chemical reactions proceed in paste matrix, which is consistent with the findings from EDS analysis that the contents of $\mathrm{Si}, \mathrm{Al}$ and $\mathrm{Ca}$ in paste matrix become close to those in ITZ (Fig. 15d). Moreover, it can be seen from Fig. 13 that the reaction products formed in paste matrix would also help refine the pore structure of paste matrix and cause a significant reduction in porosity of paste matrix from $4.17 \%(12 \mathrm{~h})$ to $1.14 \%(1 \mathrm{~d})$. The refinement of pore structure would consequently lead to a compact microstructure and a high elastic modulus in this region.

However, a sharp decrease in elastic modulus of paste matrix can be observed at $3 \mathrm{~d}$, which can be attributed to the microcracking occurred in paste matrix (Fig. 14e) and the significant decrease in volume fractions of N-C-A-S-H gels and C-A-S-H gels in paste matrix (Fig. 10b). This is due to the transport of $\mathrm{Ca}$ from paste matrix to ITZ, leading to the deficiency of $\mathrm{Ca}$ in paste matrix required for the generation of N-C-A-S-H gels and C-A-S-H gels [35].

With the increase of curing age from $3 \mathrm{~d}$ to $28 \mathrm{~d}$, the difference in elastic modulus between ITZ and paste matrix becomes less. The elastic modulus of ITZ is decreased from 18.5 GPa to 13.2 GPa, while the elastic modulus of paste matrix is increased steadily from $11.33 \mathrm{GPa}$ to $13 \mathrm{GPa}$ because of its stable chemical properties and microstructure. As seen in Fig. 10b, the volume fractions of N-AS-H, N-C-A-S-H and C-A-S-H gels in paste matrix remain stable between $3 \mathrm{~d}$ and $28 \mathrm{~d}$. Similarly, the microstructure of paste matrix is also stable during this period (Fig. 14e-g). At $28 \mathrm{~d}$, the ITZ and paste matrix have a similar elastic modulus as a result of their similar chemical composition of reaction products (Fig. 9g) and microstructural characteristics (Fig. 14g).

As discussed above, ITZ is not the weakest region in AAFS concrete at early $28 \mathrm{~d}$, considering its comparable micromechanical properties and compact microstructure compared to paste matrix. It is totally different from the ITZ found in PC concrete, which has a much smaller elastic modulus than paste matrix [16]. This is mainly because of the different chemical reactions involved in AAFS concrete and PC concrete, which result in a significant difference in the reaction products, the microstructure and consequently the micromechanical properties. In PC concrete, ITZ is often 
regarded as the weak region due to the presence of relatively high porosity as well as large calcium hydroxide $(\mathrm{CH})$ crystals $[\underline{20}, \underline{78}]$, which would lower the strength of ITZ and the interfacial bonding of aggregate and paste matrix [11]. In contrast, the main reaction products in AAFS concrete are NA-S-H, C-A-S-H and C-A-S-H gels $[\underline{10}, \underline{75}, 79]$, which would increase the strength of ITZ and interfacial bonding [28].

\section{Conclusions}

In this study, the evolution of micromechanical properties of ITZ in AAFS concrete over time is systematically investigated by means of nanoindentation, BSEM, and EDS. Based on the experimental results, the main conclusions can be drawn as follows:

- The micromechanical properties of ITZ depend on the chemical composition of reaction products and the microstructural characteristics. The ITZ with high proportion of N-C-A-S-H gels and CA-S-H gels tends to have a high elastic modulus because of their superior micromechanical properties.

- The changes in chemical composition of reaction products and microstructure of ITZ would directly affect the development of micromechanical properties in this region. At early $12 \mathrm{~h}$, the accelerated chemical reaction occurred in ITZ promotes the development of elastic modulus in this region. Between $12 \mathrm{~h}$ to $7 \mathrm{~d}$, the elastic modulus of ITZ fluctuates between 17.68 $\mathrm{GPa}$ and 21.21 GPa, due to the stable transformation among N-A-S-H, N-C-A-S-H and C-A-S-H gels. The decrease of elastic modulus of ITZ between $7 \mathrm{~d}$ and $28 \mathrm{~d}$ can be ascribed to the reduction of free $\mathrm{Ca}$ content and propagation of microcracks in this region.

- The evolution of micromechanical properties of ITZ can be divided into three stages: (i) accelerated growth stage via fast chemical reactions $(<12 \mathrm{~h})$; (ii) stationary stage via stable chemical reactions (12 h-7 d); and (iii) decrement stage via microcrack propagation (7 d-28 d).

- ITZ in AAFS concrete at early $28 \mathrm{~d}$ is not the weakest region owing to its desired micromechanical properties and compact microstructure compared to paste matrix.

It should be noted that the micromechanical properties of ITZ in AAFS concrete are highly dependent on its mix proportions, which would influence the formation of reaction products and the development of microstructure as well as the micromechanical properties of ITZ. In addition, the characteristics of aggregate in terms of size, shape and surface texture would also affect the micromechanical properties of ITZ. For future work, it would be interesting to investigate the effects of mix proportions and aggregate characteristics on the micromechanical properties of ITZ in AAFS concrete.

\section{Acknowledgements}

The authors gratefully acknowledge the financial support from the Engineering and Physical Sciences Research Council (EPSRC), UK under Grant No. EP/R041504/1 and the Royal Society, UK under 
Award No. IEC\NSFC $\backslash 191417$ as well as the Visiting Researcher Fund Program of State Key Laboratory of Water Resources and Hydropower Engineering Science, China under Award No. 2019SGG01. The financial support provided by University College London (UCL) and China Scholarship Council (CSC) to the first author is gratefully acknowledged.

\section{References}

[1] F. Puertas, S. Martínez-Ramírez, S. Alonso, T. Vázquez, Alkali-activated fly ash/slag cements: Strength behaviour and hydration products, Cement and Concrete Research 30(10) (2000) 1625-1632. [2] N.K. Lee, H.K. Lee, Setting and mechanical properties of alkali-activated fly ash/slag concrete manufactured at room temperature, Construction and Building Materials 47 (2013) 1201-1209.

[3] J.G. Jang, N.K. Lee, H.K. Lee, Fresh and hardened properties of alkali-activated fly ash/slag pastes with superplasticizers, Construction and Building Materials 50 (2014) 169-176.

[4] G. Fang, W.K. Ho, W. Tu, M. Zhang, Workability and mechanical properties of alkali-activated fly ash-slag concrete cured at ambient temperature, Construction and Building Materials 172 (2018) 476-487.

[5] W.C. Wang, H.Y. Wang, M.H. Lo, The fresh and engineering properties of alkali activated slag as a function of fly ash replacement and alkali concentration, Construction and Building Materials 84 (2015) 224-229.

[6] P. Nath, P.K. Sarker, Effect of GGBFS on setting, workability and early strength properties of fly ash geopolymer concrete cured in ambient condition, Construction and Building Materials 66 (2014) 163-171.

[7] Z. Pan, Z. Tao, Y.F. Cao, R. Wuhrer, T. Murphy, Compressive strength and microstructure of alkali-activated fly ash/slag binders at high temperature, Cement and Concrete Composites 86 (2018) 9-18.

[8] M.C. Chi, H. Chen, T.L. Weng, R. Huang, Y.C. Wang, Durability of Alkali-Activated Fly Ash/Slag Concrete, Materials Science Forum 904 (2017) 157-161.

[9] S. Puligilla, P. Mondal, Role of slag in microstructural development and hardening of fly ash-slag geopolymer, Cement and Concrete Research 43 (2013) 70-80.

[10] H. Ye, A. Radlińska, Fly ash-slag interaction during alkaline activation: Influence of activators on phase assemblage and microstructure formation, Construction and Building Materials 122 (2016) 594-606.

[11] K.L. Scrivener, A.K. Crumbie, P. Laugesen, The interfacial transition zone (ITZ) between cement paste and aggregate in concrete, Interface Science 12(4) (2004) 411-421.

[12] J.P. Ollivier, J.C. Maso, B. Bourdette, Interfacial transition zone in concrete, Advanced Cement Based Materials 2(1) (1995) 30-38.

[13] P. Trtik, P.J.M. Bartos, Micromechanical properties of cementitious composites, Materials and 
Structures 33(2) (2000) 144-144.

[14] X. Fan, M. Zhang, Behaviour of inorganic polymer concrete columns reinforced with basalt FRP bars under eccentric compression: An experimental study, Composites Part B: Engineering 104 (2016) 44-56.

[15] X. Fan, M. Zhang, Experimental study on flexural behaviour of inorganic polymer concrete beams reinforced with basalt rebar, Composites Part B: Engineering 93 (2016) 174-183.

[16] P. Mondal, S.P. Shah, L.D. Marks, Nanomechanical Properties of Interfacial Transition Zone in Concrete, Springer Berlin Heidelberg, Berlin, Heidelberg, 2009, pp. 315-320.

[17] A. Bentur, M.G. Alexander, R.T. Comm, A review of the work of the RILEM TC 159-ETC: Engineering of the interfacial transition zone in cementitious composites, Materials and Structures 33(226) (2000) 82-87.

[18] T. Akçaoğlu, M. Tokyay, T. Çelik, Assessing the ITZ microcracking via scanning electron microscope and its effect on the failure behavior of concrete, Cement and Concrete Research 35(2) (2005) 358-363.

[19] H.S. Wong, M. Zobel, N.R. Buenfeld, R.W. Zimmerman, Influence of the interfacial transition zone and microcracking on the diffusivity, permeability and sorptivity of cement-based materials after drying, Magazine of Concrete Research 61(8) (2009) 571-589.

[20] A.W. Pope, H.M. Jennings, The influence of mixing on the microstructure of the cement paste/aggregate interfacial zone and on the strength of mortar, Journal of Materials Science 27(23) (1992) 6452-6462.

[21] M. Khedmati, Y.-R. Kim, J.A. Turner, H. Alanazi, C. Nguyen, An integrated microstructuralnanomechanical-chemical approach to examine material-specific characteristics of cementitious interphase regions, Materials Characterization 138 (2018) 154-164.

[22] A. Elsharief, M.D. Cohen, J. Olek, Influence of aggregate size, water cement ratio and age on the microstructure of the interfacial transition zone, Cement and Concrete Research 33(11) (2003) 1837-1849.

[23] P. Simeonov, S. Ahmad, Effect of transition zone on the elastic behavior of cement-based composites, Cement and Concrete Research 25(1) (1995) 165-176.

[24] T. Akçaoğlu, M. Tokyay, T. Çelik, Effect of coarse aggregate size and matrix quality on ITZ and failure behavior of concrete under uniaxial compression, Cement and Concrete Composites 26(6) (2004) 633-638.

[25] W.K.W. Lee, J.S.J. van Deventer, The interface between natural siliceous aggregates and geopolymers, Cement and Concrete Research 34(2) (2004) 195-206.

[26] P.K. Sarker, R. Haque, K.V. Ramgolam, Fracture behaviour of heat cured fly ash based geopolymer concrete, Materials and Design 44 (2013) 580-586. 
[27] T. Ji, Q.L. Gao, W.Y. Zheng, X.J. Lin, H.C. Wu, Interfacial transition zone of alkali-activated slag concrete, ACI Materials Journal 114(3) (2017) 347-354.

[28] R.S. Nicolas, J.L. Provis, The interfacial transition zone in alkali-activated slag mortars, Front Mater 2 (2015).

[29] A.R. Brough, A. Atkinson, Sodium silicate-based, alkali-activated slag mortars: Part I. Strength, hydration and microstructure, Cement and Concrete Research 32(6) (2002) 865-879.

[30] S.A. Bernal, R. Mejía de Gutiérrez, A.L. Pedraza, J.L. Provis, E.D. Rodriguez, S. Delvasto, Effect of binder content on the performance of alkali-activated slag concretes, Cement and Concrete Research 41(1) (2011) 1-8.

[31] Y. Ding, J. Dai, C. Shi, Fracture properties of alkali-activated slag and ordinary Portland cement concrete and mortar, Construction and Building Materials 165 (2018) 310-320.

[32] C. Shi, P. Xie, Interface between cement paste and quartz sand in alkali-activated slag mortars, Cement and Concrete Research 28(6) (1998) 887-896.

[33] Y. Tajunnisa, M. Sugimoto, T. Uchinuno, T. Sato, Y. Toda, A. Hamasaki, T. Yoshinaga, K. Shida, M. Shigeishi, Performance of alkali-activated fly ash incorporated with GGBFS and micro-silica in the interfacial transition zone, microstructure, flowability, mechanical properties and drying shrinkage, AIP Conference Proceedings 1887(1) (2017) 020034.

[34] B. Singh, M.R. Rahman, R. Paswan, S.K. Bhattacharyya, Effect of activator concentration on the strength, ITZ and drying shrinkage of fly ash/slag geopolymer concrete, Construction and Building Materials 118 (2016) 171-179.

[35] G. Fang, M. Zhang, The evolution of interfacial transition zone in alkali-activated fly ash-slag concrete, Cement and Concrete Research 129 (2020) 105963.

[36] A. Fernández-Jiménez, A. Palomo, Characterisation of fly ashes. Potential reactivity as alkaline cements $\preccurlyeq$, Fuel 82(18) (2003) 2259-2265.

[37] D. Li, Z. Xu, Z. Luo, Z. Pan, L. Cheng, The activation and hydration of glassy cementitious materials, Cement and Concrete Research 32(7) (2002) 1145-1152.

[38] P.Z. Wang, R. Trettin, V. Rudert, Effect of fineness and particle size distribution of granulated blast-furnace slag on the hydraulic reactivity in cement systems, Advances in Cement Research 17(4) (2005) 161-167.

[39] N.Y. Mostafa, S.A.S. El-Hemaly, E.I. Al-Wakeel, S.A. El-Korashy, P.W. Brown, Characterization and evaluation of the hydraulic activity of water-cooled slag and air-cooled slag, Cement and Concrete Research 31(6) (2001) 899-904.

[40] BS EN 196-1:2016, Methods of testing cement Part 1: Determination of strength, BSI, 2016.

[41] P.S. Deb, P. Nath, P.K. Sarker, The effects of ground granulated blast-furnace slag blending with fly ash and activator content on the workability and strength properties of geopolymer concrete cured 
at ambient temperature, Materials and Design 62 (2014) 32-39.

[42] H. Alanazi, J. Hu, Y.R. Kim, Effect of slag, silica fume, and metakaolin on properties and performance of alkali-activated fly ash cured at ambient temperature, Construction and Building Materials 197 (2019) 747-756.

[43] M. Talha Junaid, O. Kayali, A. Khennane, J. Black, A mix design procedure for low calcium alkali activated fly ash-based concretes, Construction and Building Materials 79 (2015) 301-310.

[44] BS EN 197-1:2011, Cement part 1: Composition, specifications and conformity criteria for common cements, BSI Standards Publication, 2011.

[45] ACI M318-05, Building Code Requirements for Structural Concrete and Commentary, American Concrete Institute, 2005.

[46] S.H. Kosmatka, B. Kerkhoff, W.C. Panarese, Design and Control of Concrete Mixtures, Portland Cement Association, Skokie, Illinois, 2002.

[47] J. Zhang, G.W. Scherer, Comparison of methods for arresting hydration of cement, Cement and Concrete Research 41(10) (2011) 1024-1036.

[48] Z. Zhang, Y. Zhu, H. Zhu, Y. Zhang, J.L. Provis, H. Wang, Effect of drying procedures on pore structure and phase evolution of alkali-activated cements, Cement and Concrete Composites 96 (2019) 194-203.

[49] I. Ismail, S.A. Bernal, J.L. Provis, S. Hamdan, J.S.J. van Deventer, Drying-induced changes in the structure of alkali-activated pastes, Journal of Materials Science 48(9) (2013) 3566-3577.

[50] J. Xiao, W. Li, Z. Sun, D.A. Lange, S.P. Shah, Properties of interfacial transition zones in recycled aggregate concrete tested by nanoindentation, Cement and Concrete Composites 37 (2013) 276-292.

[51] C. Hu, Z. Li, A review on the mechanical properties of cement-based materials measured by nanoindentation, Construction and Building Materials 90 (2015) 80-90.

[52] C. Hu, Z. Li, Property investigation of individual phases in cementitious composites containing silica fume and fly ash, Cement and Concrete Composites 57 (2015) 17-26.

[53] C. Hu, Microstructure and mechanical properties of fly ash blended cement pastes, Construction and Building Materials 73 (2014) 618-625.

[54] W.C. Oliver, G.M. Pharr, An improved technique for determining hardness and elastic modulus using load and displacement sensing indentation experiments, Journal of Materials Research 7(6) (2011) 1564-1583.

[55] A.C. Fischer-Cripps, Nanoindentation, Springer-Verlag, New York, 2004.

[56] R.J. Thomas, S. Peethamparan, Alkali-activated concrete: Engineering properties and stressstrain behavior, Construction and Building Materials 93 (2015) 49-56.

[57] M. Sofi, J.S.J. van Deventer, P. Mendis, G.C. Lukey, Engineering properties of inorganic polymer 
concretes (IPCs), Cement and Concrete Research 37(2) (2007) 251-257.

[58] X. Zhu, Y. Yuan, L. Li, Y. Du, F. Li, Identification of interfacial transition zone in asphalt concrete based on nano-scale metrology techniques, Materials and Design 129 (2017) 91-102.

[59] H. Buckle, Applications to other material properties, in: J.H. Westbrook, H. Conrad (Eds.), The science of hardness testing and its applications, Ohio, 1973.

[60] J. Tatar, C.R. Taylor, H.R. Hamilton, A multiscale micromechanical model of adhesive interphase between cement paste and epoxy supported by nanomechanical evidence, Composites Part B: Engineering 172 (2019) 679-689.

[61] N.X. Randall, M. Vandamme, F.-J. Ulm, Nanoindentation analysis as a two-dimensional tool for mapping the mechanical properties of complex surfaces, Journal of Materials Research 24(3) (2011) 679-690.

[62] G. Constantinides, K.S. Ravi Chandran, F.J. Ulm, K.J. Van Vliet, Grid indentation analysis of composite microstructure and mechanics: Principles and validation, Materials Science and Engineering: A 430(1) (2006) 189-202.

[63] G. Fang, M. Zhang, Multiscale micromechanical analysis of alkali-activated fly ash-slag paste, Cement and Concrete Research 135 (2020) 106141.

[64] M. Nedeljković, B. Šavija, Y. Zuo, M. Luković, G. Ye, Effect of natural carbonation on the pore structure and elastic modulus of the alkali-activated fly ash and slag pastes, Construction and Building Materials 161 (2018) 687-704.

[65] J. Němecek, V. Smilauer, L. Kopecky, J. Německová, Nanoindentation of Alkali-Activated Fly Ash, Transportation Research Record 2141(1) (2010) 36-40.

[66] R.J. Thomas, B.S. Gebregziabiher, A. Giffin, S. Peethamparan, Micromechanical properties of alkali-activated slag cement binders, Cement and Concrete Composites 90 (2018) 241-256.

[67] J. Schindelin, I. Arganda-Carreras, E. Frise, V. Kaynig, M. Longair, T. Pietzsch, S. Preibisch, C. Rueden, S. Saalfeld, B. Schmid, J.-Y. Tinevez, D.J. White, V. Hartenstein, K. Eliceiri, P. Tomancak, A. Cardona, Fiji: an open-source platform for biological-image analysis, Nature Methods 9(7) (2012) 676-682.

[68] J. Němeček, V. Šmilauer, L. Kopecký, Nanoindentation characteristics of alkali-activated aluminosilicate materials, Cement and Concrete Composites 33(2) (2011) 163-170.

[69] R. Cao, S. Zhang, N. Banthia, Y. Zhang, Z. Zhang, Interpreting the early-age reaction process of alkali-activated slag by using combined embedded ultrasonic measurement, thermal analysis, XRD, FTIR and SEM, Composites Part B: Engineering 186 (2020) 107840.

[70] S.K. Nath, S. Kumar, Reaction kinetics, microstructure and strength behavior of alkali activated silico-manganese (SiMn) slag - Fly ash blends, Construction and Building Materials 147 (2017) 371379. 
[71] Y. Jin, D. Stephan, The unusual solidification process of alkali activated slag and its relationship with the glass structure of the slag, Cement and Concrete Research 121 (2019) 1-10.

[72] N. Li, C. Shi, Z. Zhang, Understanding the roles of activators towards setting and hardening control of alkali-activated slag cement, Composites Part B: Engineering 171 (2019) 34-45.

[73] K.C. Reddy, C. Gudur, K.V.L. Subramaniam, Study on the influences of silica and sodium in the alkali-activation of ground granulated blast furnace slag, Construction and Building Materials 257 (2020) 119514.

[74] U. De Filippis, E. Prud'homme, S. Meille, Relation between activator ratio, hydration products and mechanical properties of alkali-activated slag, Construction and Building Materials 266 (2021) 120940.

[75] I. García-Lodeiro, A. Fernández-Jiménez, A. Palomo, Variation in hybrid cements over time. Alkaline activation of fly ash-portland cement blends, Cement and Concrete Research 52 (2013) 112 122.

[76] Y. Gao, G. De Schutter, G. Ye, H. Huang, Z. Tan, K. Wu, Porosity characterization of ITZ in cementitious composites: Concentric expansion and overflow criterion, Construction and Building Materials 38 (2013) 1051-1057.

[77] J. Xiao, W. Li, D.J. Corr, S.P. Shah, Effects of interfacial transition zones on the stress-strain behavior of modeled recycled aggregate concrete, Cement and Concrete Research 52 (2013) 82-99. [78] J.A. Larbi, J.M.J.M. Bijen, Effects of water-cement ratio, quantity and fineness of sand on the evolution of lime in set portland cement systems, Cement and Concrete Research 20(5) (1990) 783794.

[79] F. Pacheco-Torgal, J.A. Labrincha, C. Leonelli, A. Palomo, P. Chindaprasirt, Handbook of alkaliactivated cements, mortars and concretes, Woodhead Publishing 2014. 


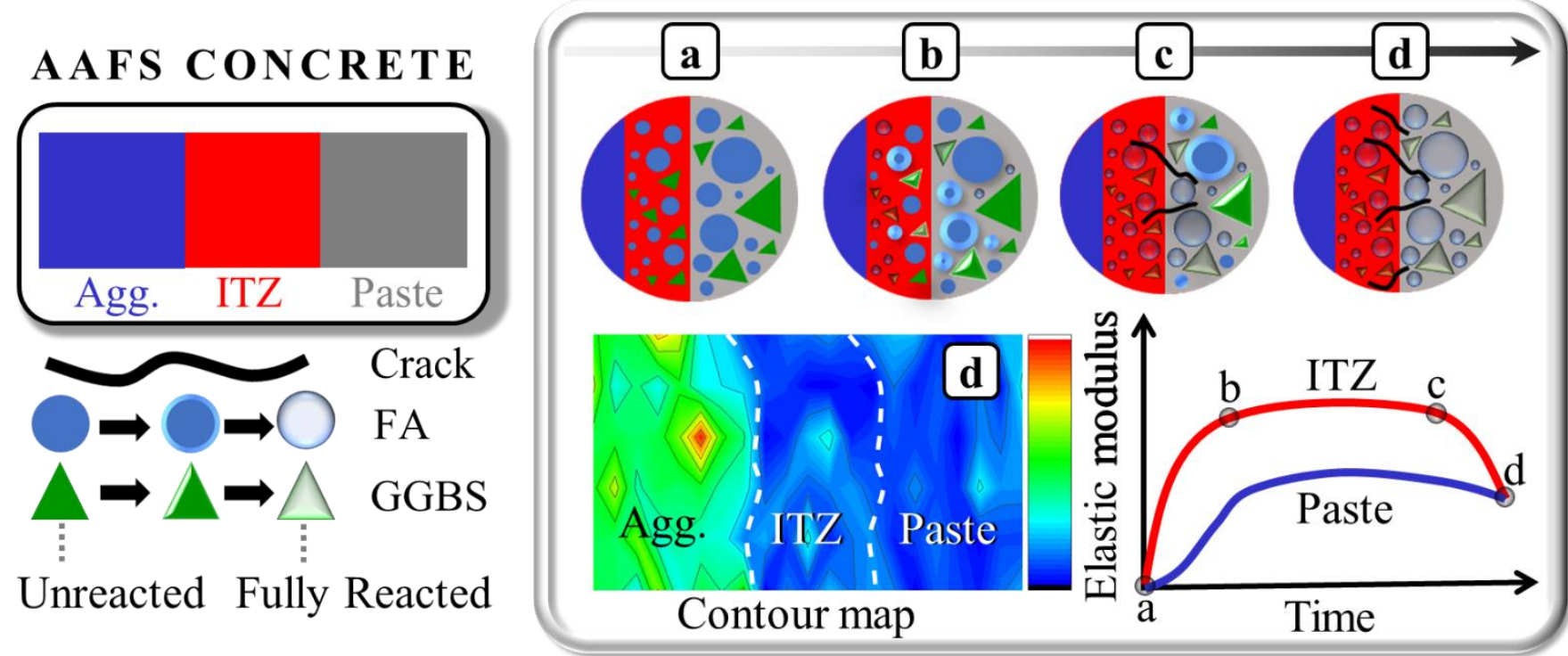


(a)

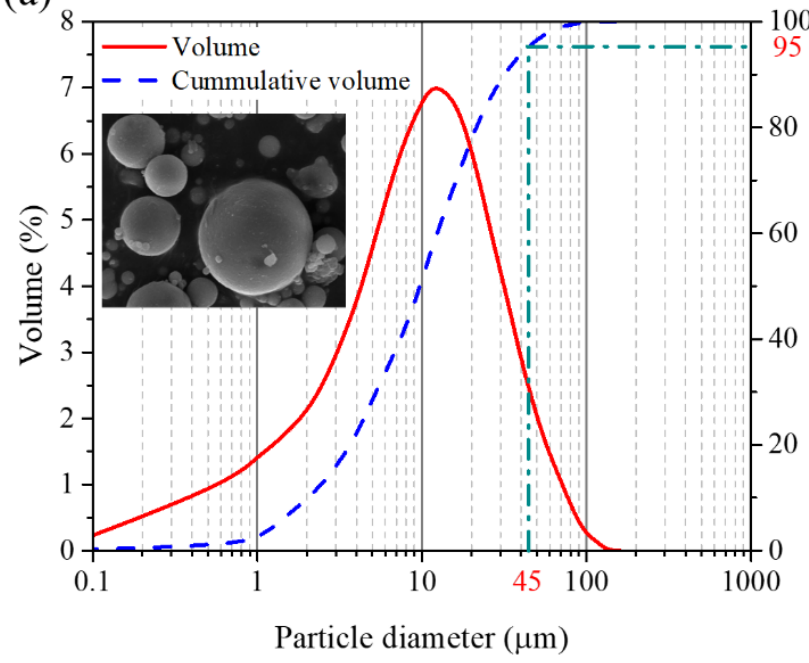

(b)

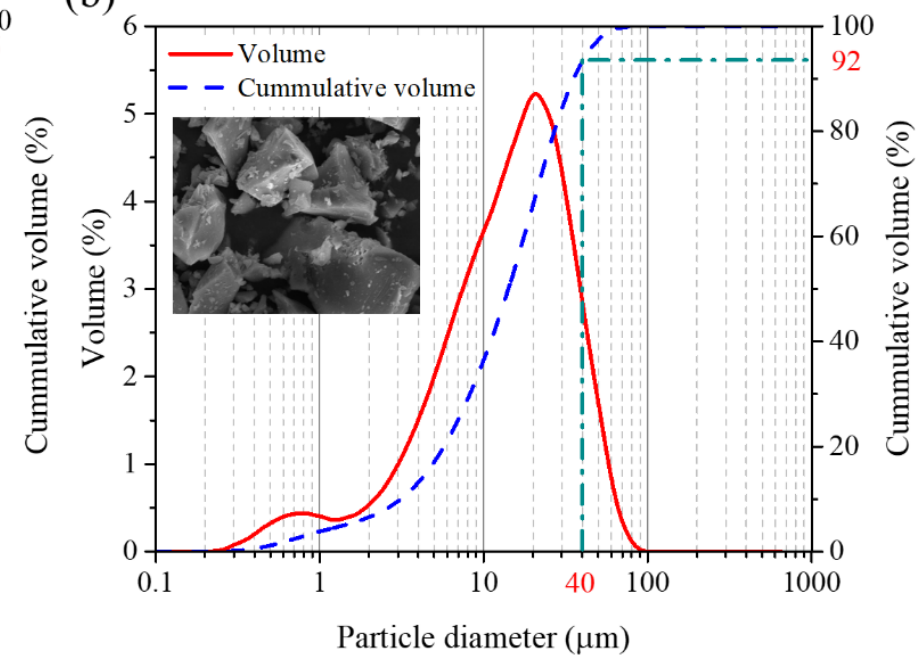

Fig. 1. Particle size distribution of FA (a) and GGBS (b)

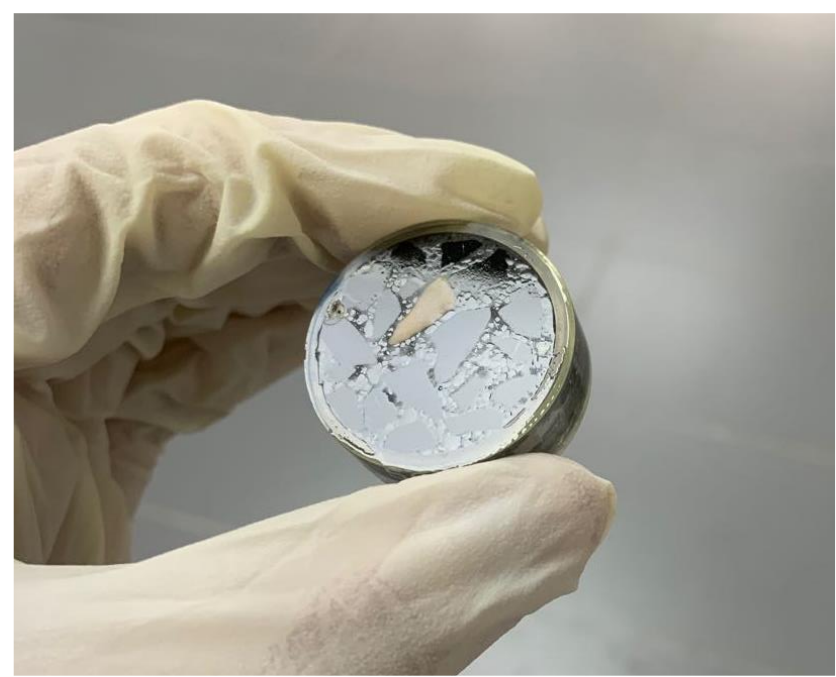

Fig. 2. AAFS concrete sample after grinding and polishing 


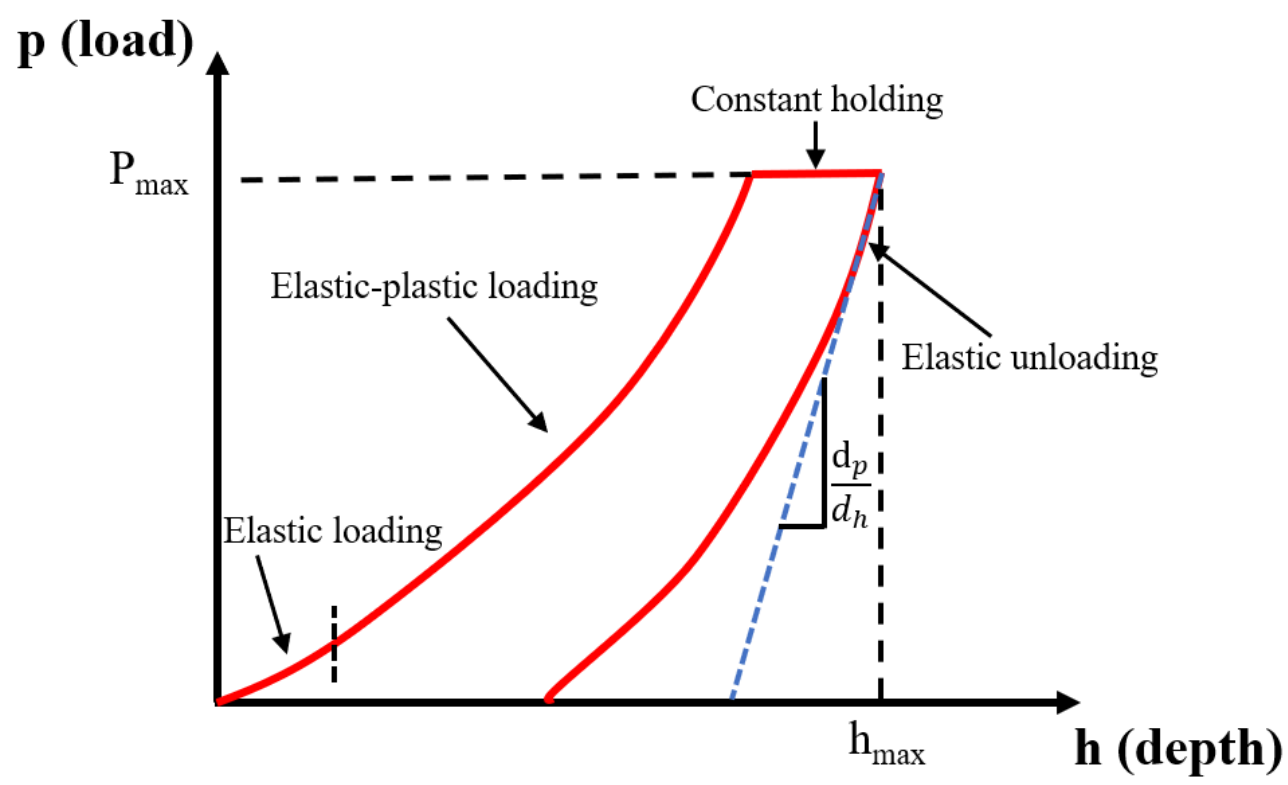

Fig. 3. A typical load-depth curve of nanoindentation test (after [48])

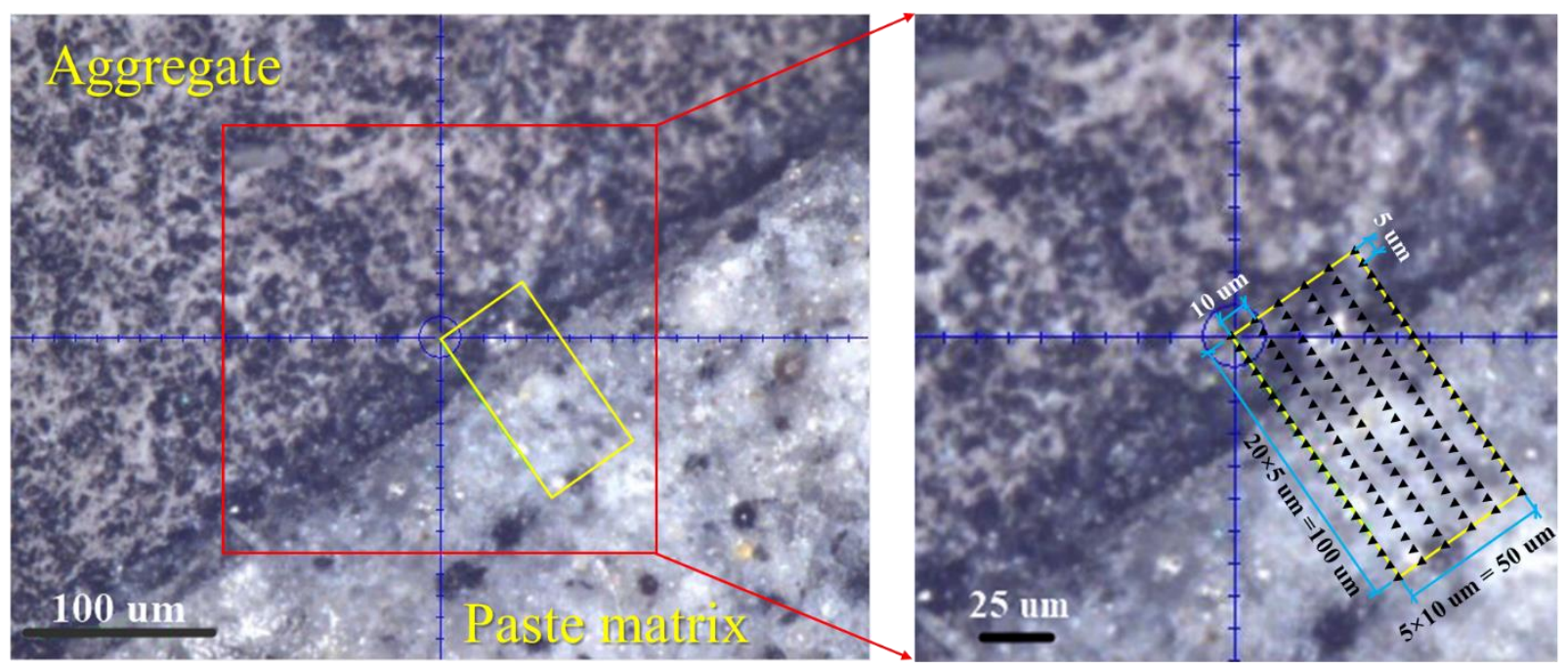

Fig. 4. Schematic illustration of the indented area 


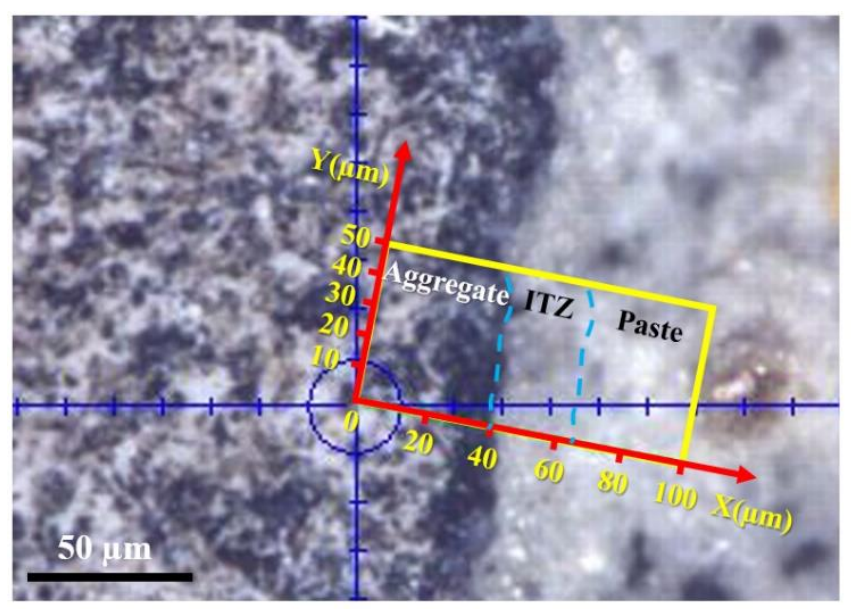

(a) Indent area: $100 \times 50 \mu \mathrm{m}$

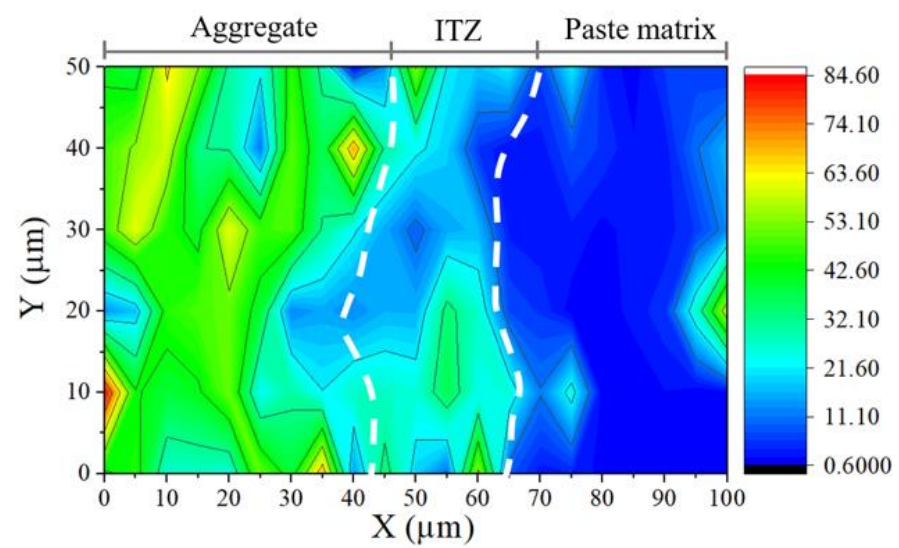

(c) Contour map of elastic modulus

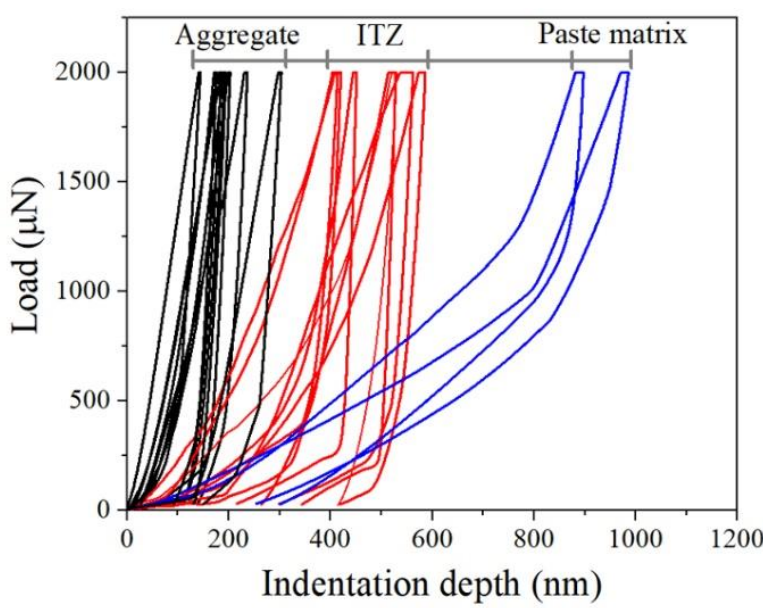

(b) Load-depth curves of indent area

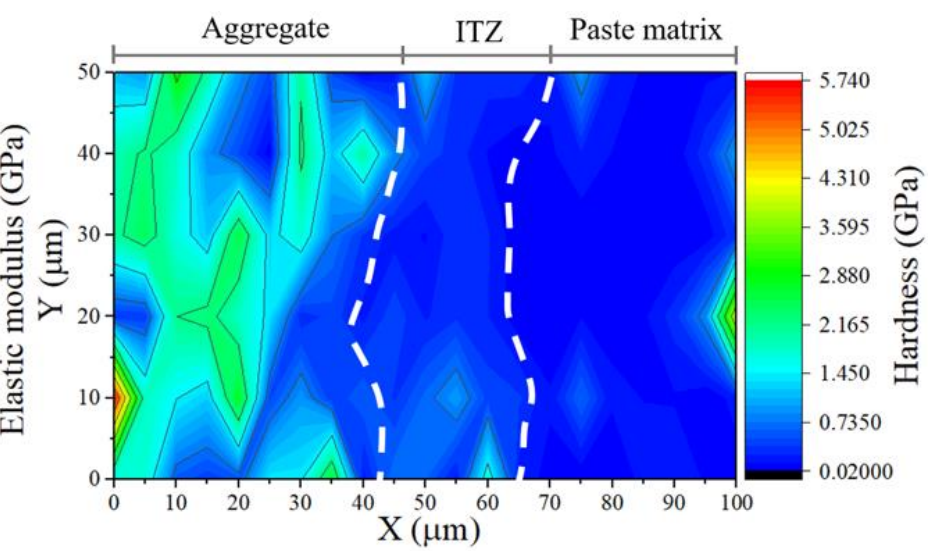

(d) Contour map of hardness

Fig. 5. Testing results of grid nanoindentation of AAFS concrete $(t=6 h)$ 
(a)

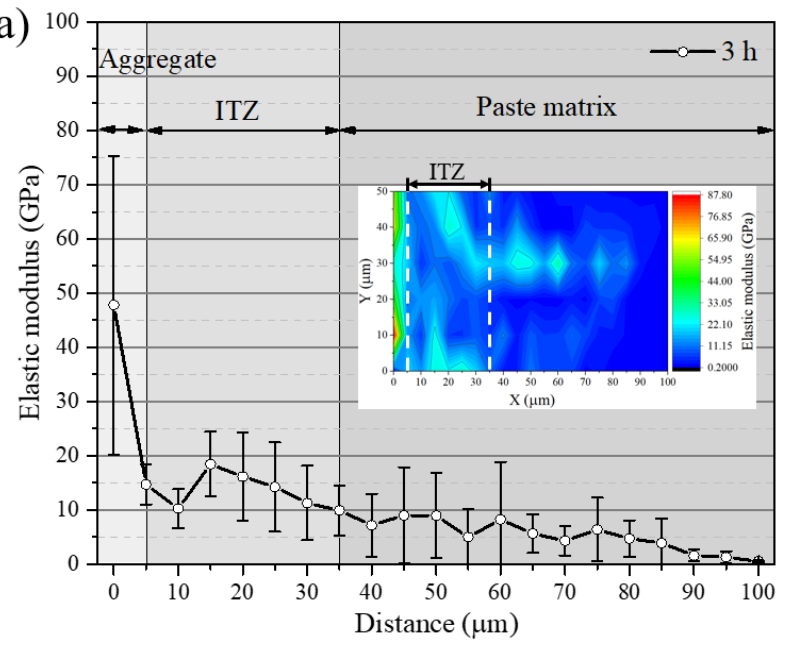

(b)

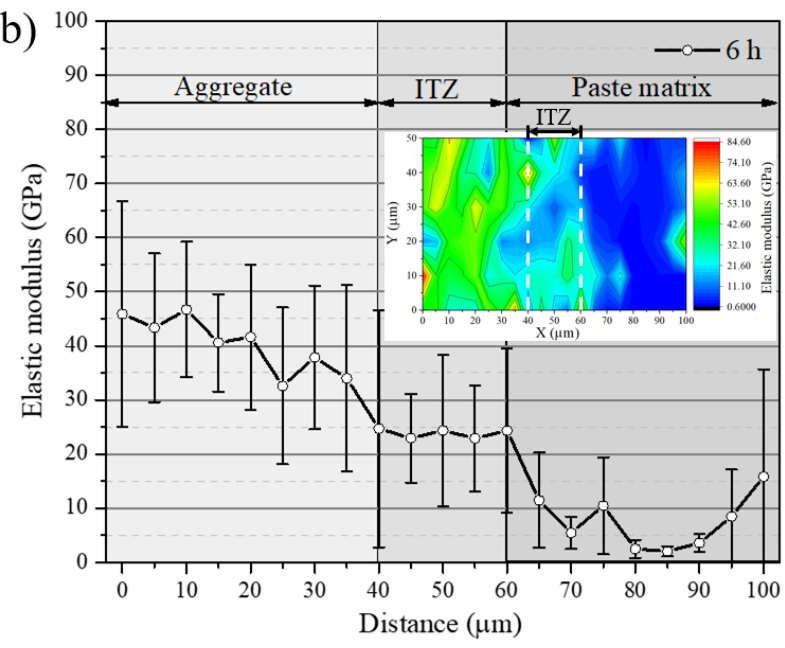

(c)

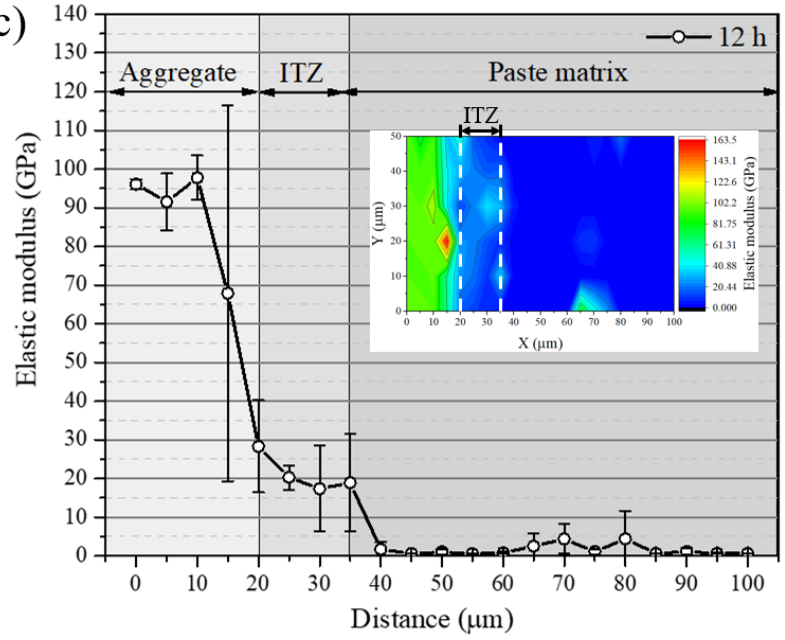

(d)

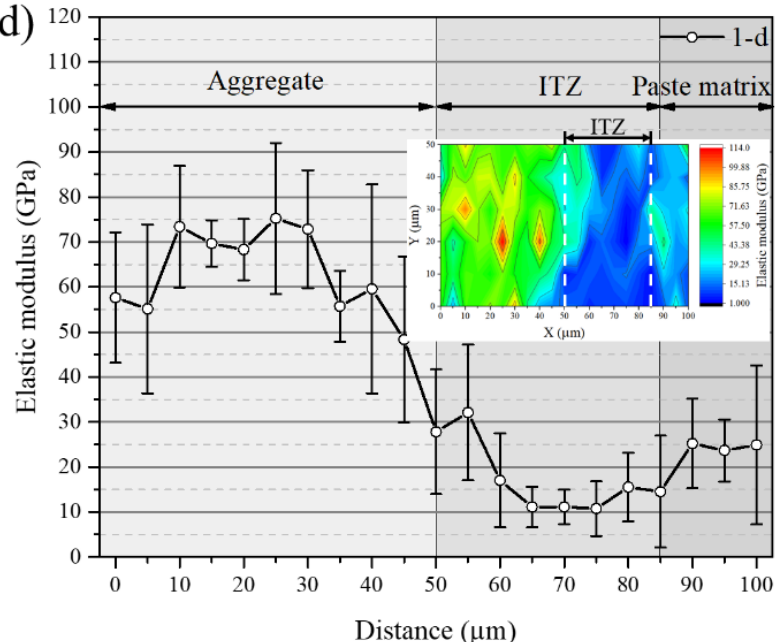

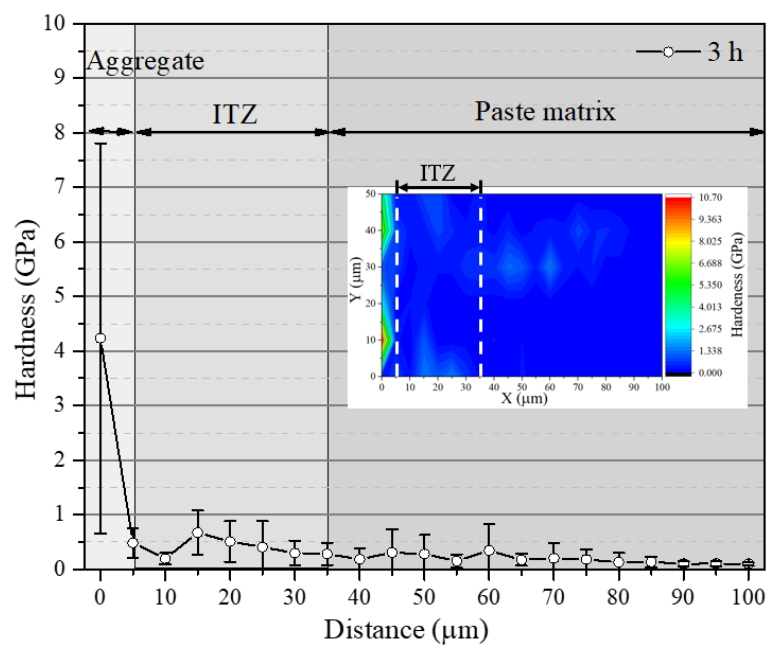
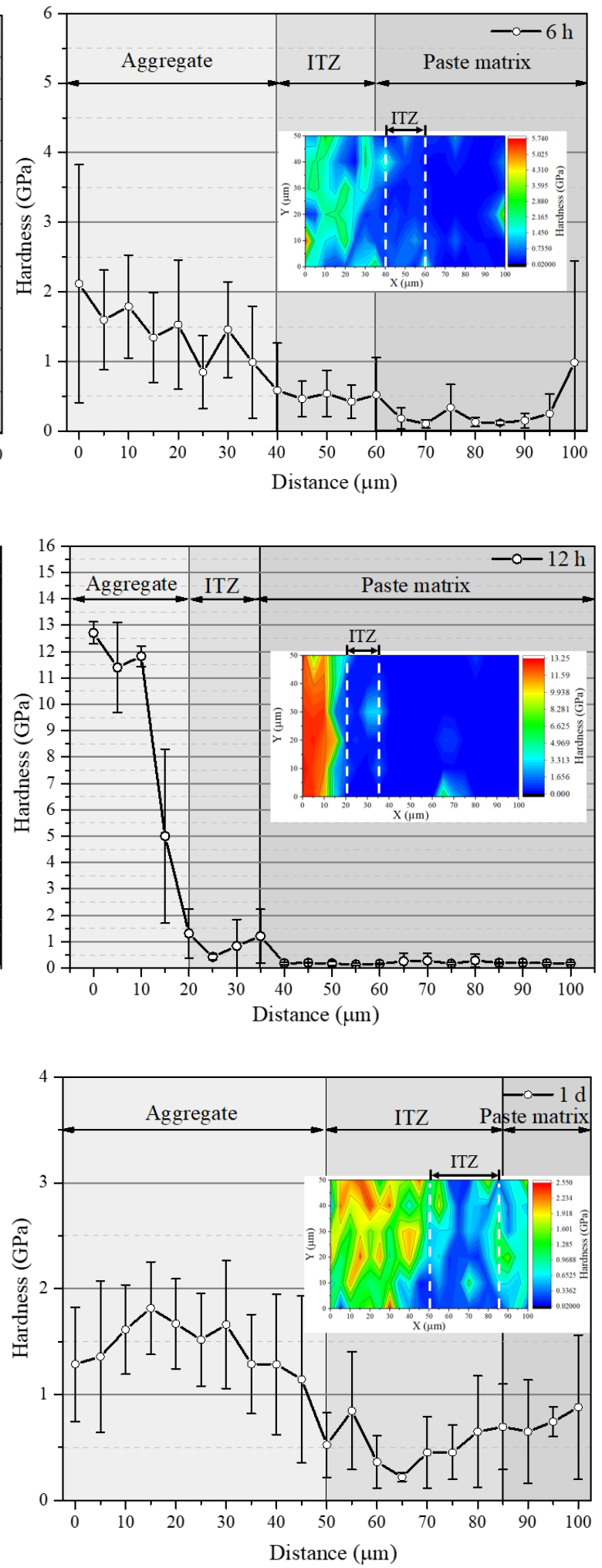
(e)

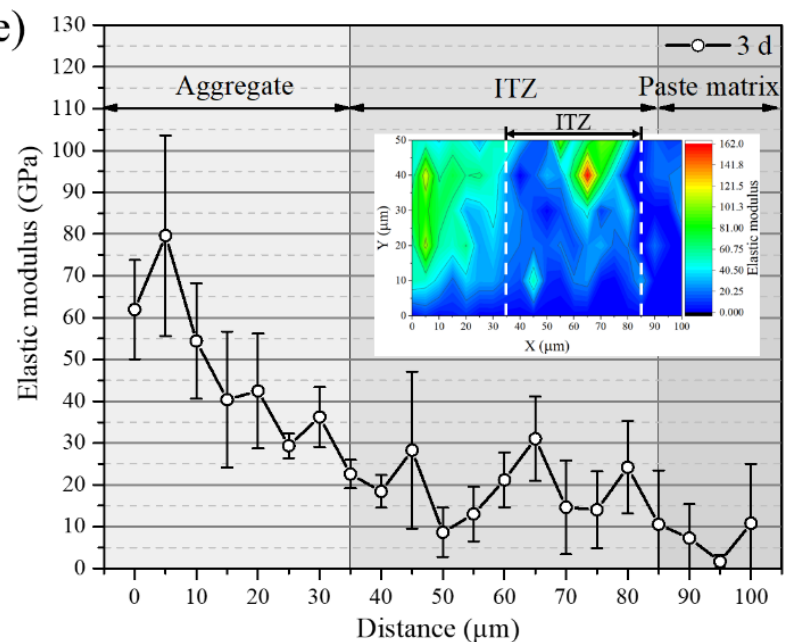

(f)

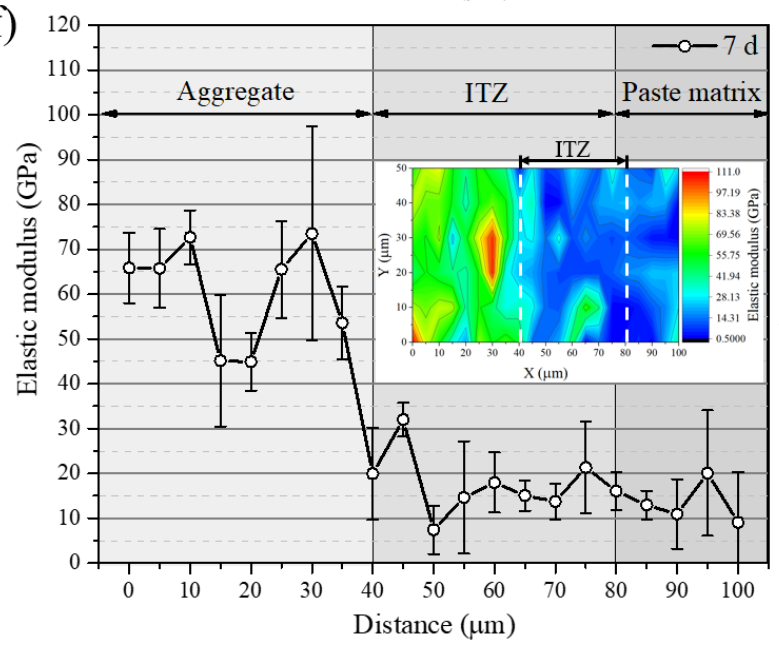

(g)

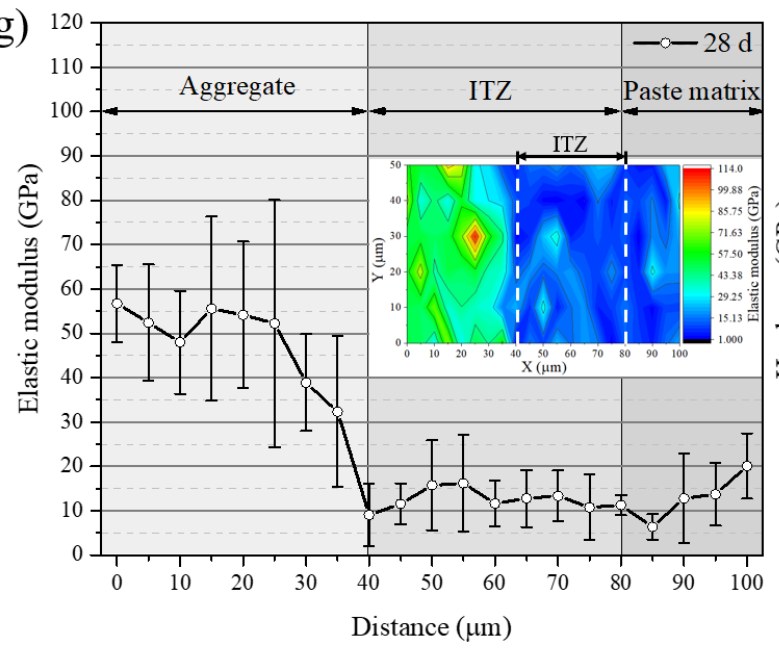

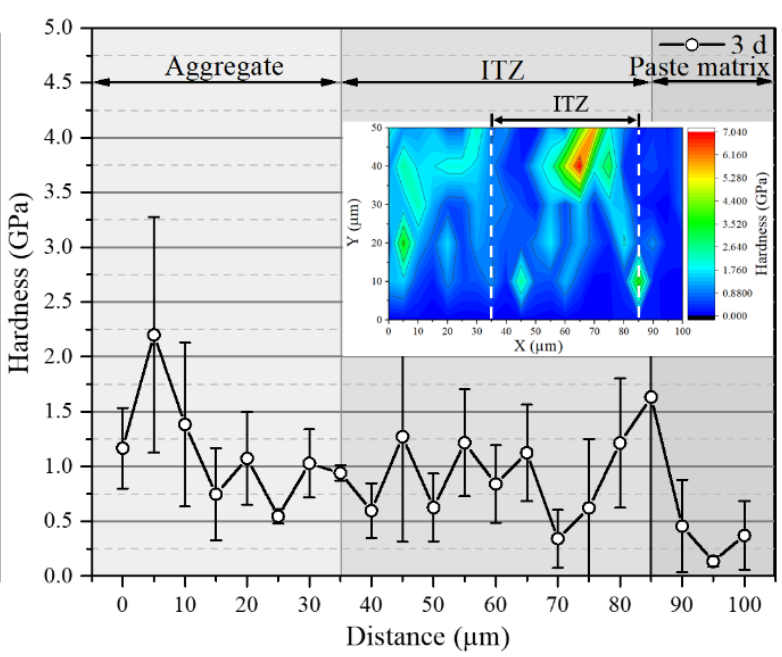
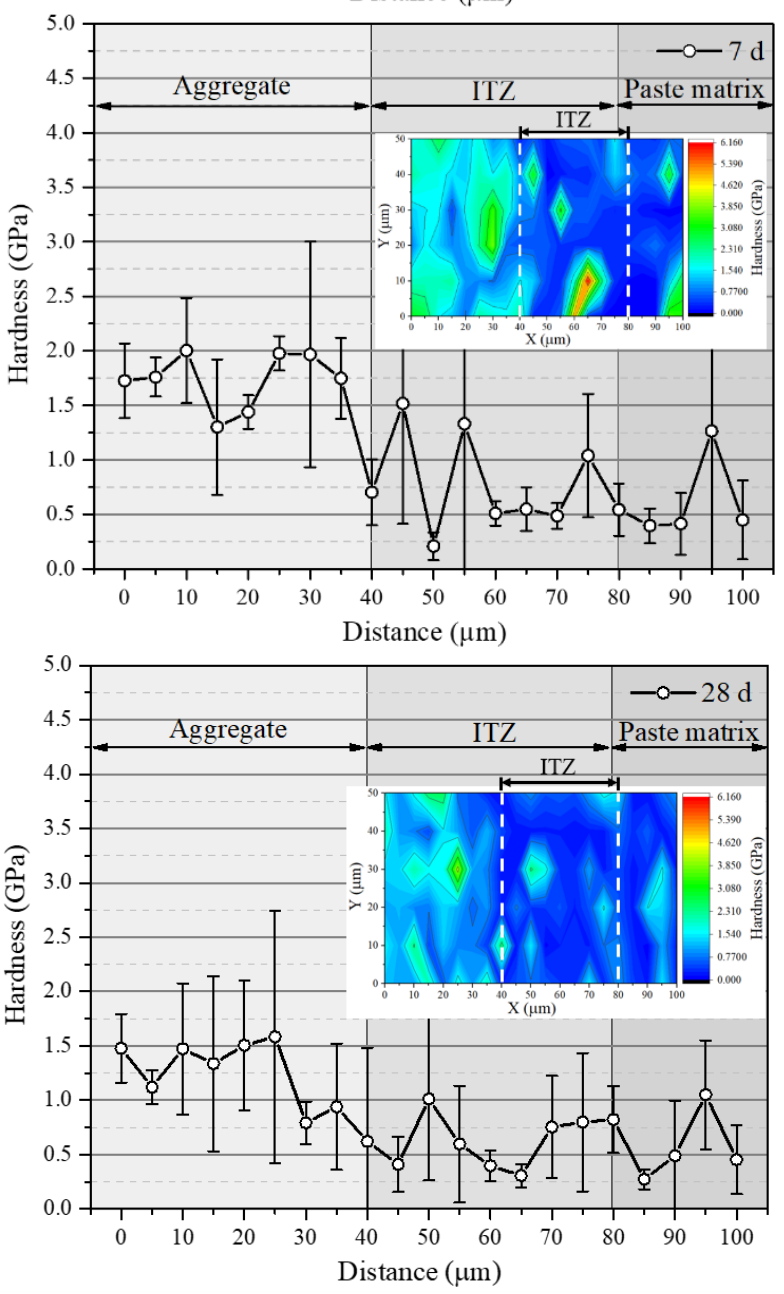

Fig. 6. Histogram of elastic modulus and hardness of AAFS concrete at different curing ages 
(a)

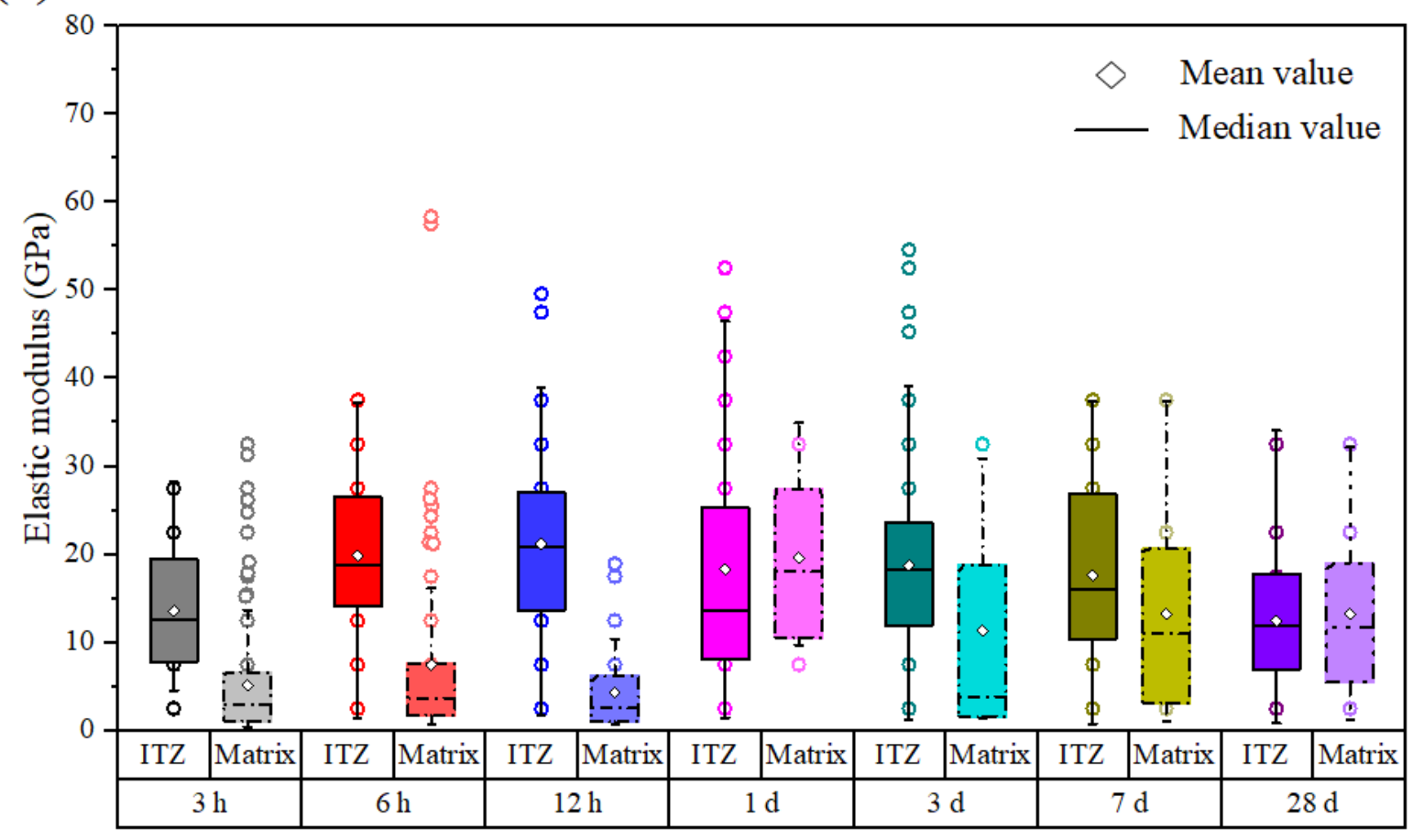

(b)

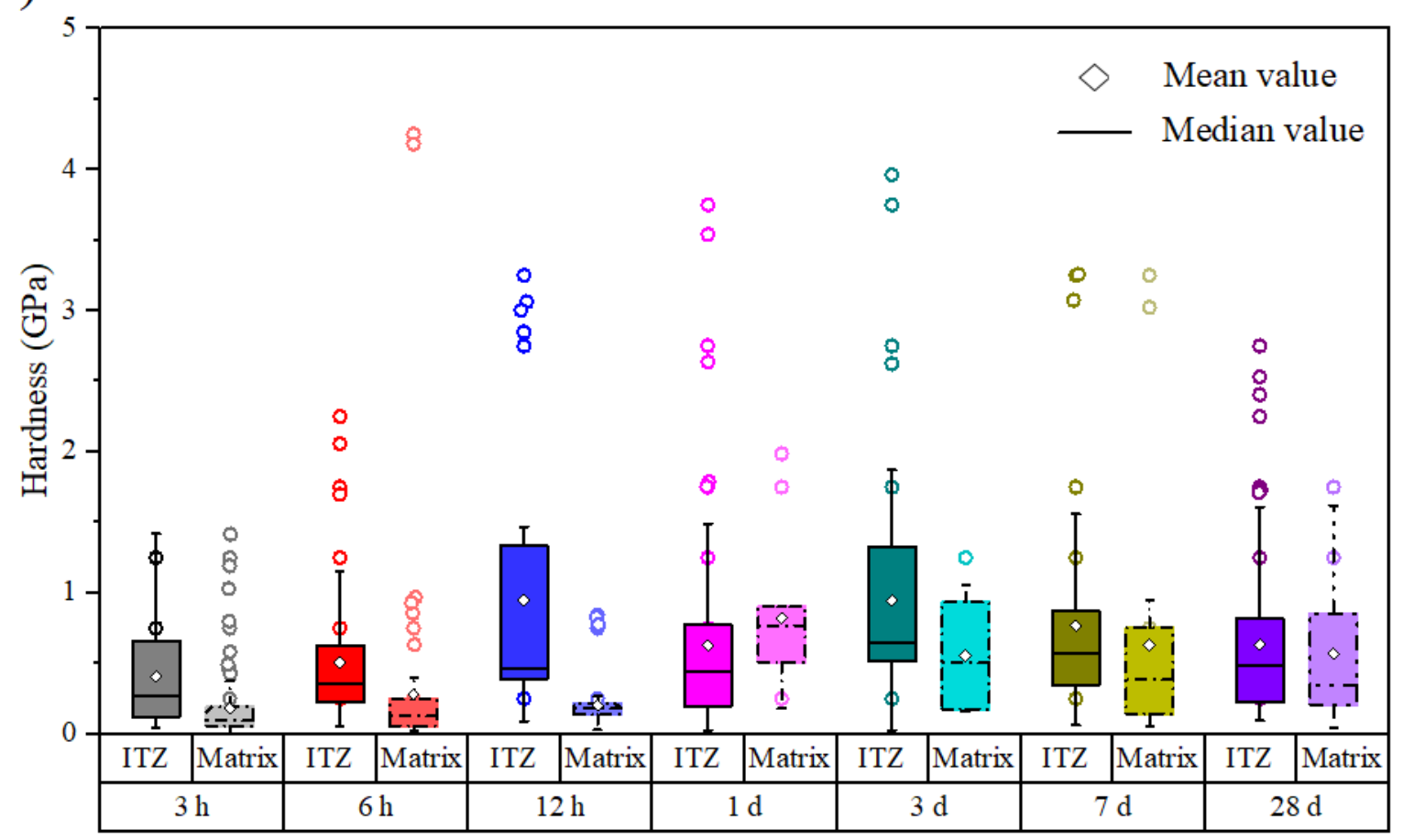

Fig. 7. Elastic modulus (a) and hardness (b) of ITZ and paste matrix of AAFS concrete at different curing ages 


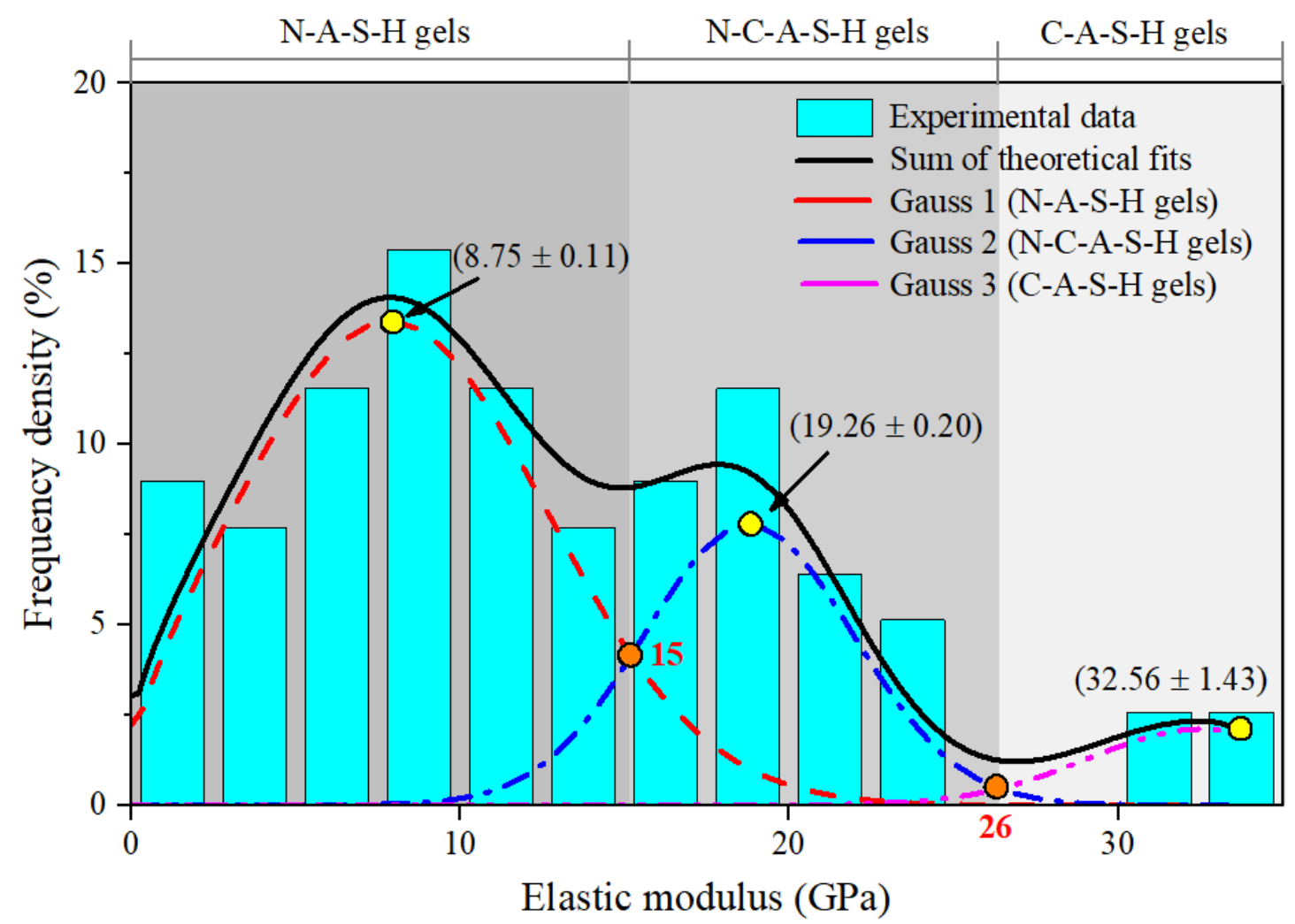

Fig. 8 Gaussian deconvolution of frequency density for elastic modulus of reaction products in AAFS concrete $(\mathrm{t}=28 \mathrm{~d})$ 
(a) $3 \mathrm{~h}$

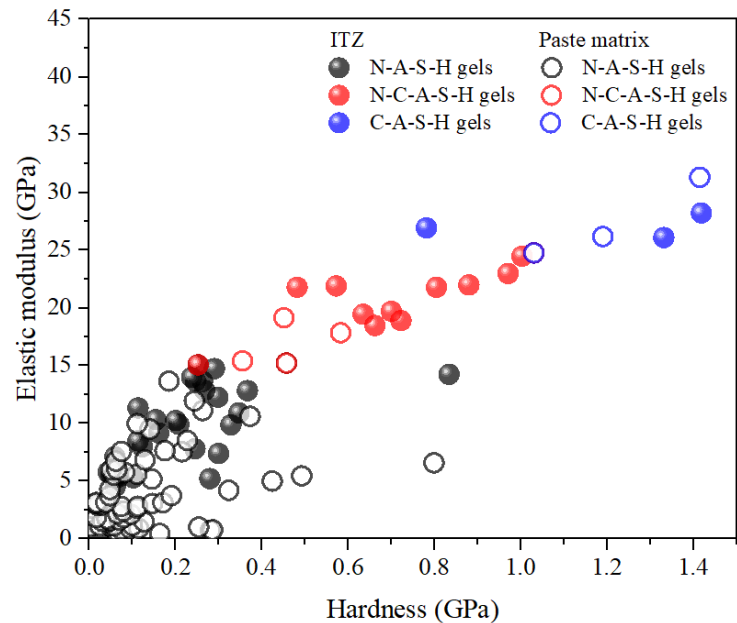

(b) $6 \mathrm{~h}$

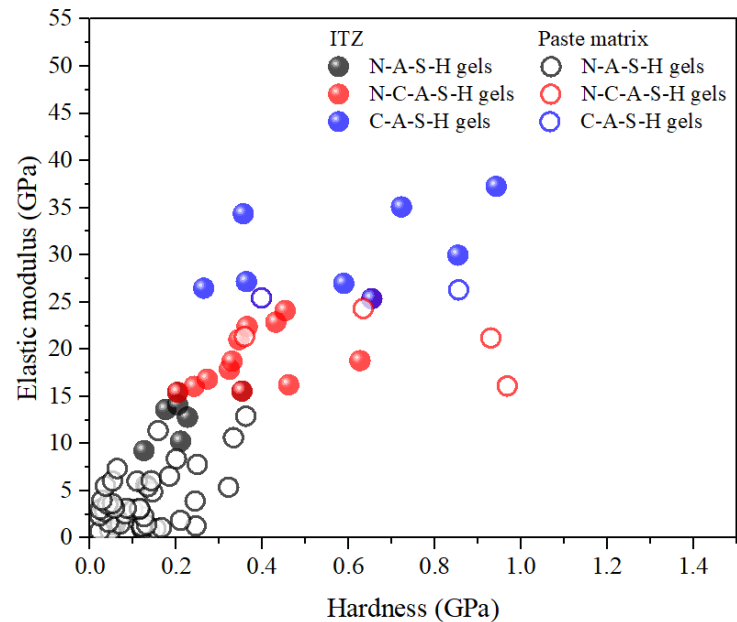

(c) $12 \mathrm{~h}$

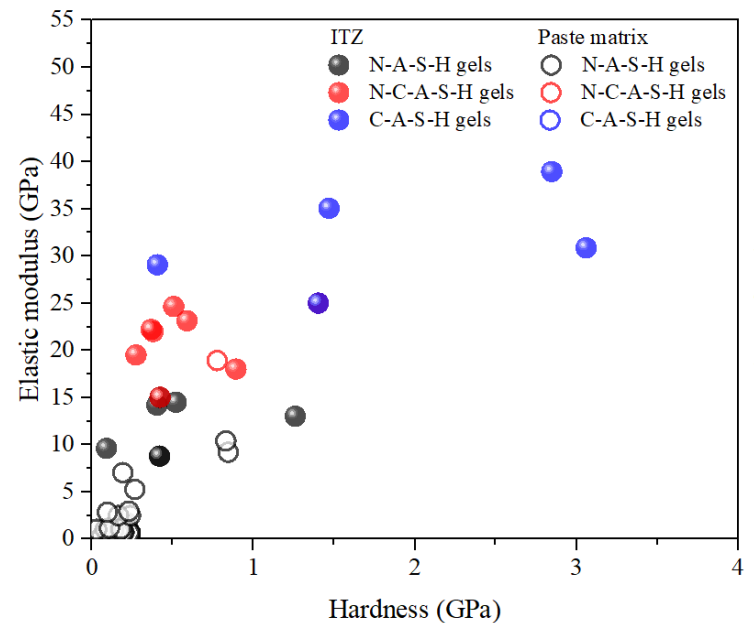

(d) $1 \mathrm{~d}$

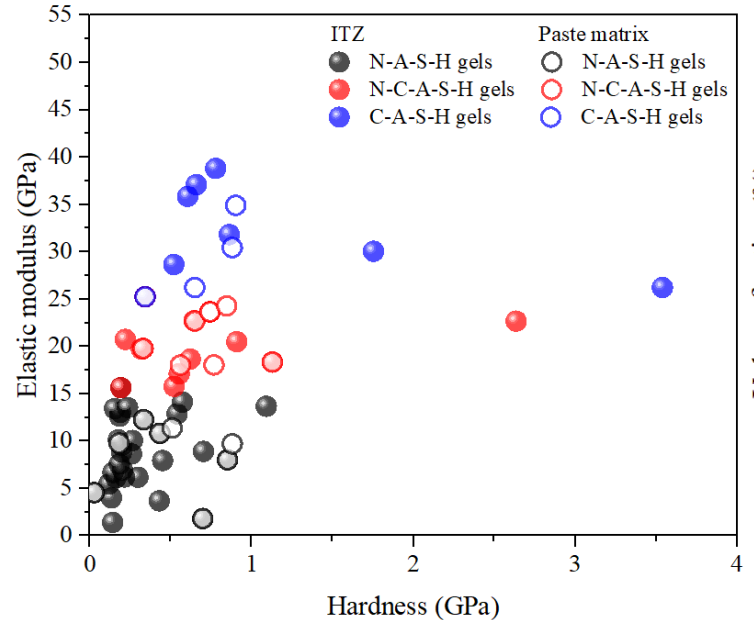

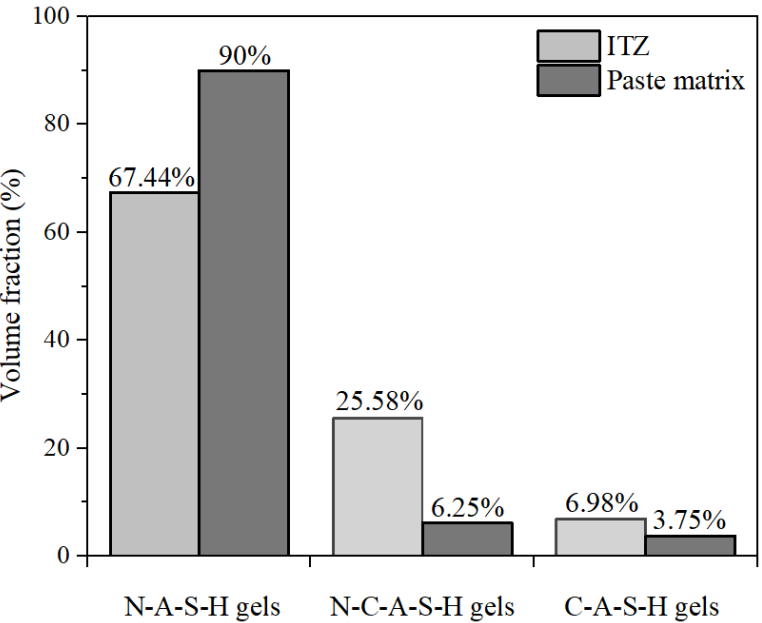
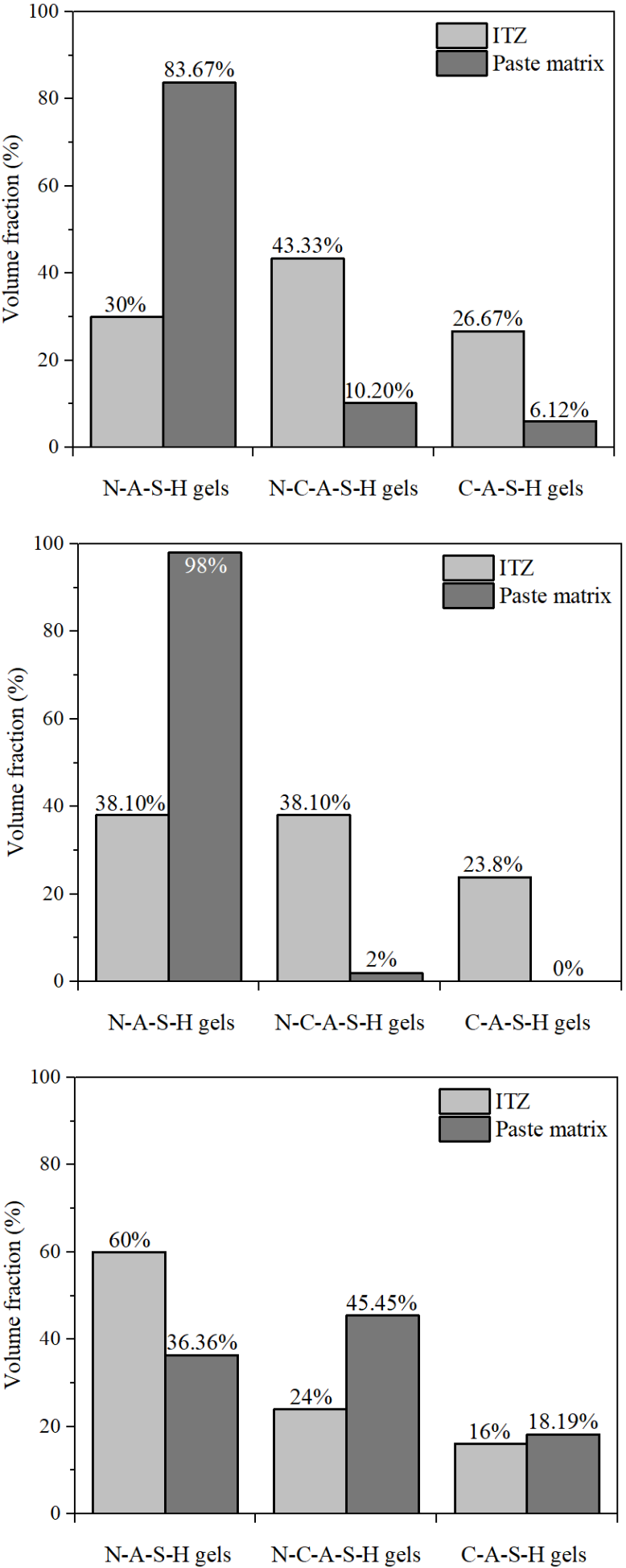
(e) $3 \mathrm{~d}$

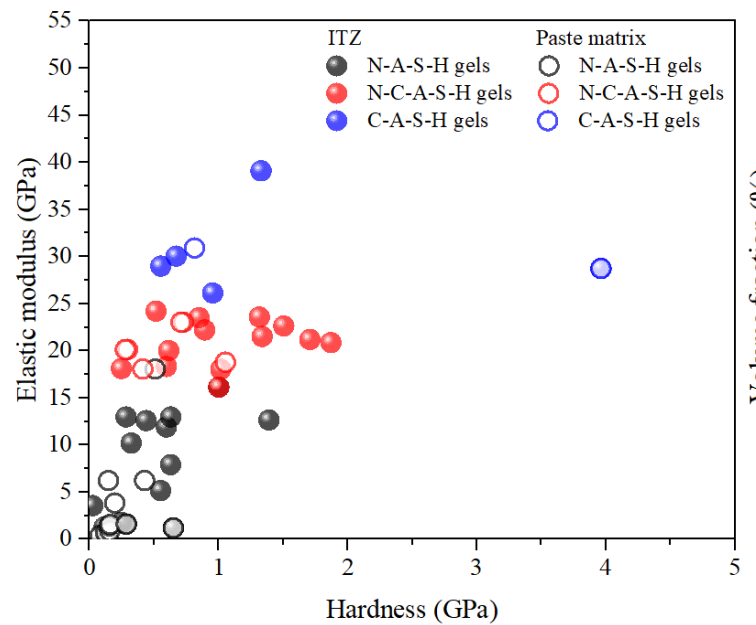

(f) $7 \mathrm{~d}$

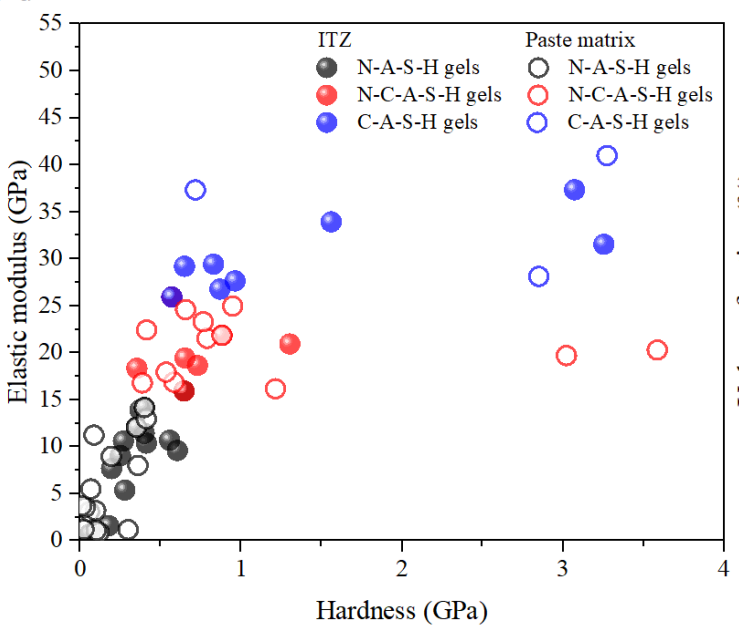

(g) $28 \mathrm{~d}$

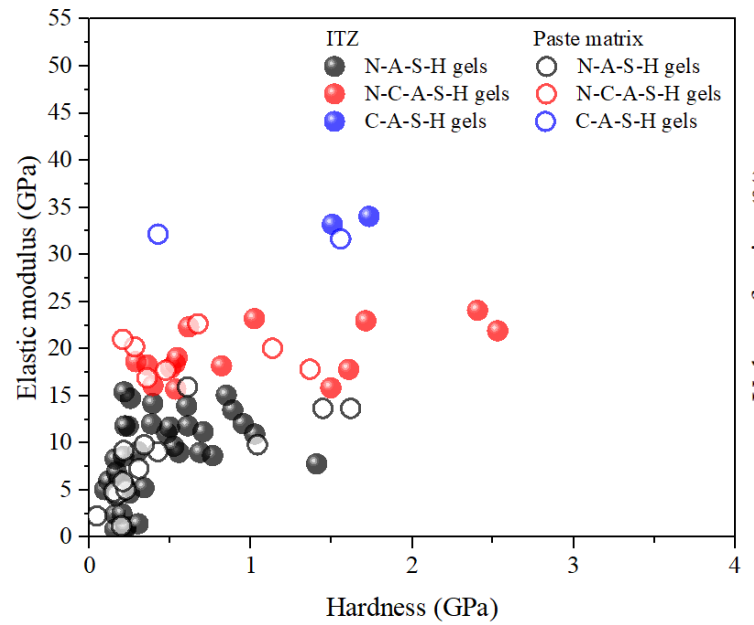

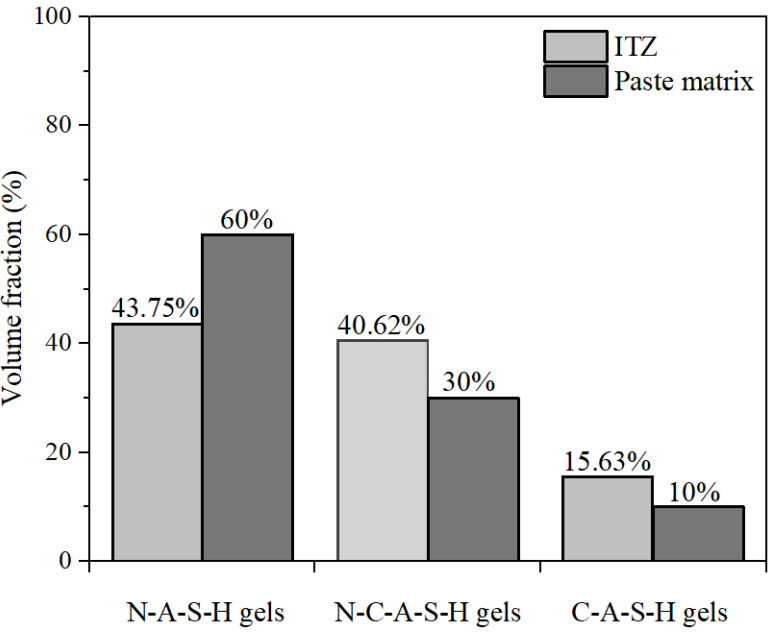
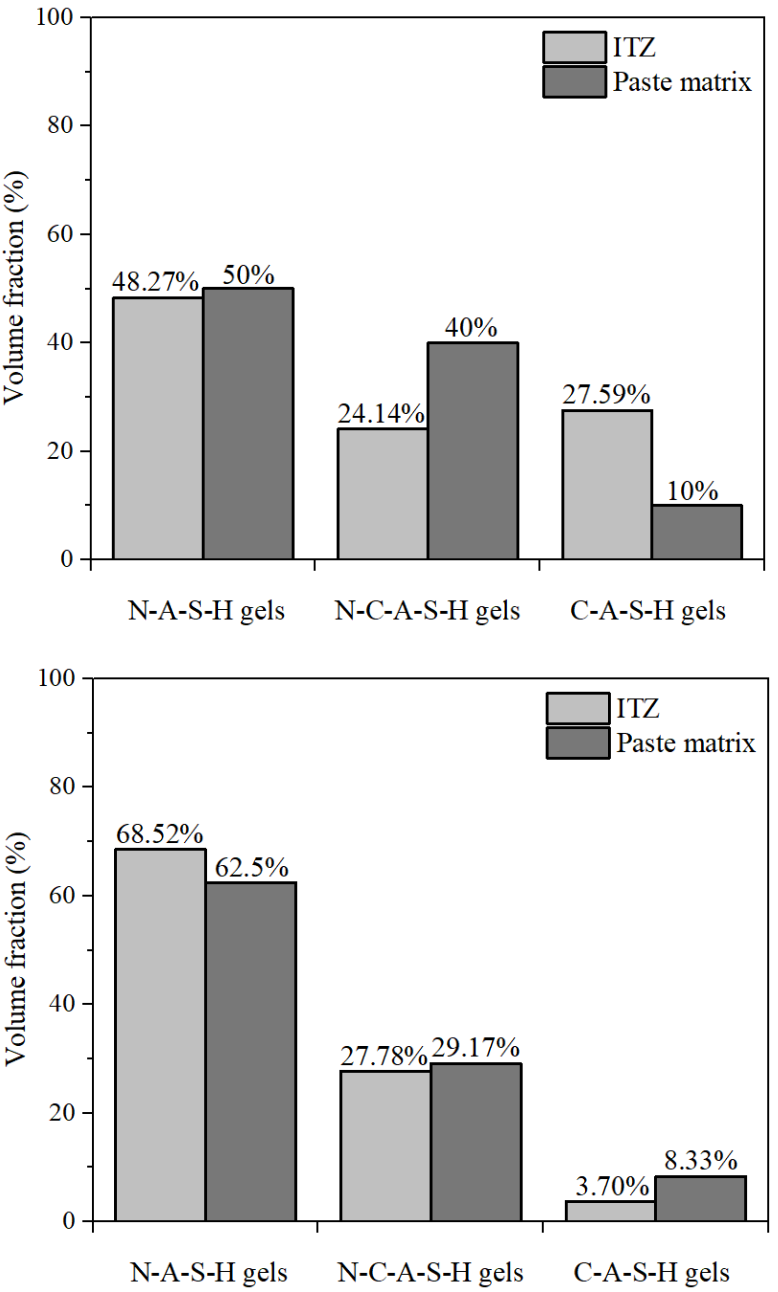

Fig. 9. Micromechanical properties of reaction products in ITZ and paste matrix of AAFS concrete at different curing ages: cluster allocation of elastic modulus and hardness (left); volume fraction of different reaction products (right) 
(a)

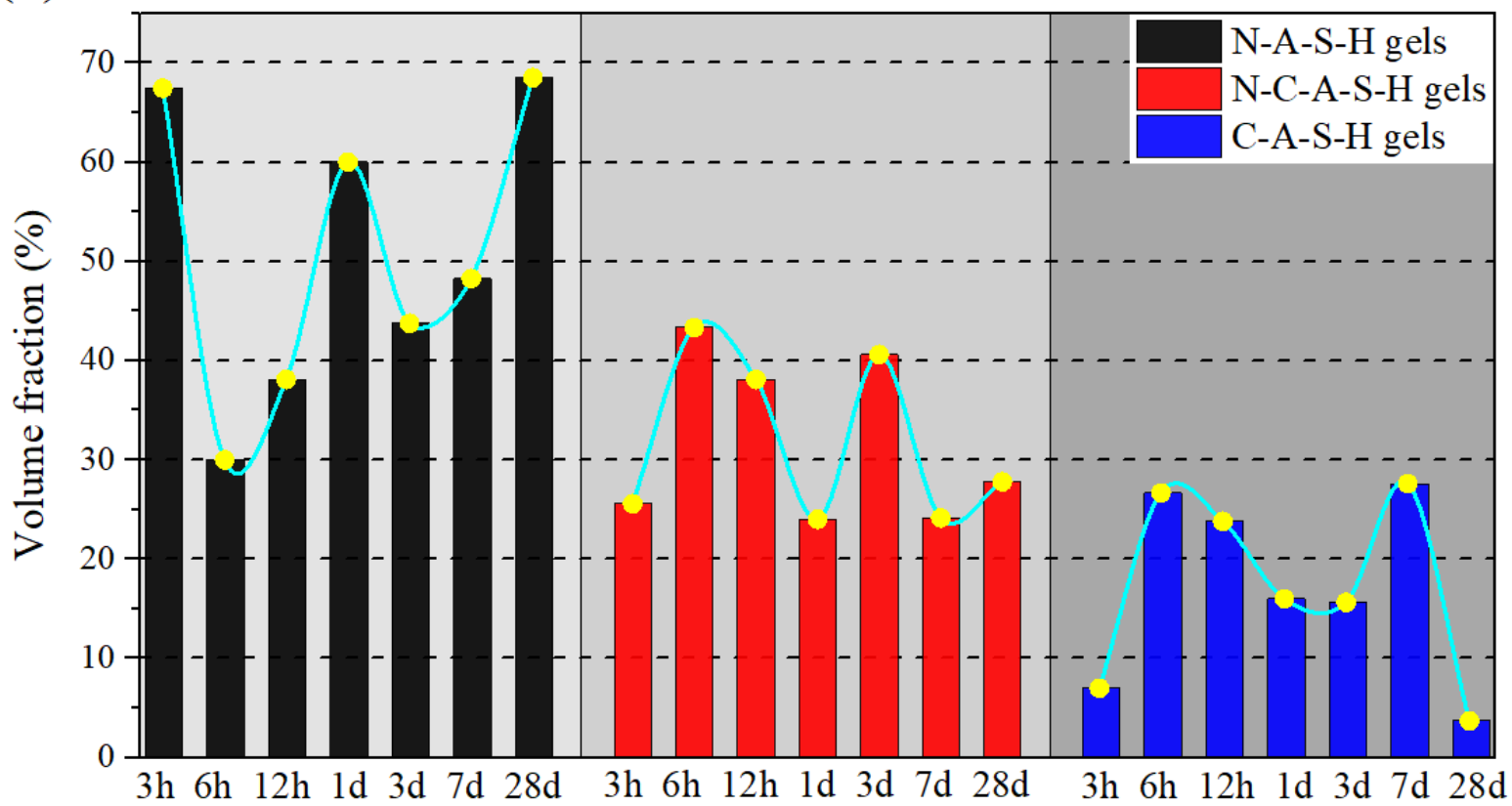

(b)

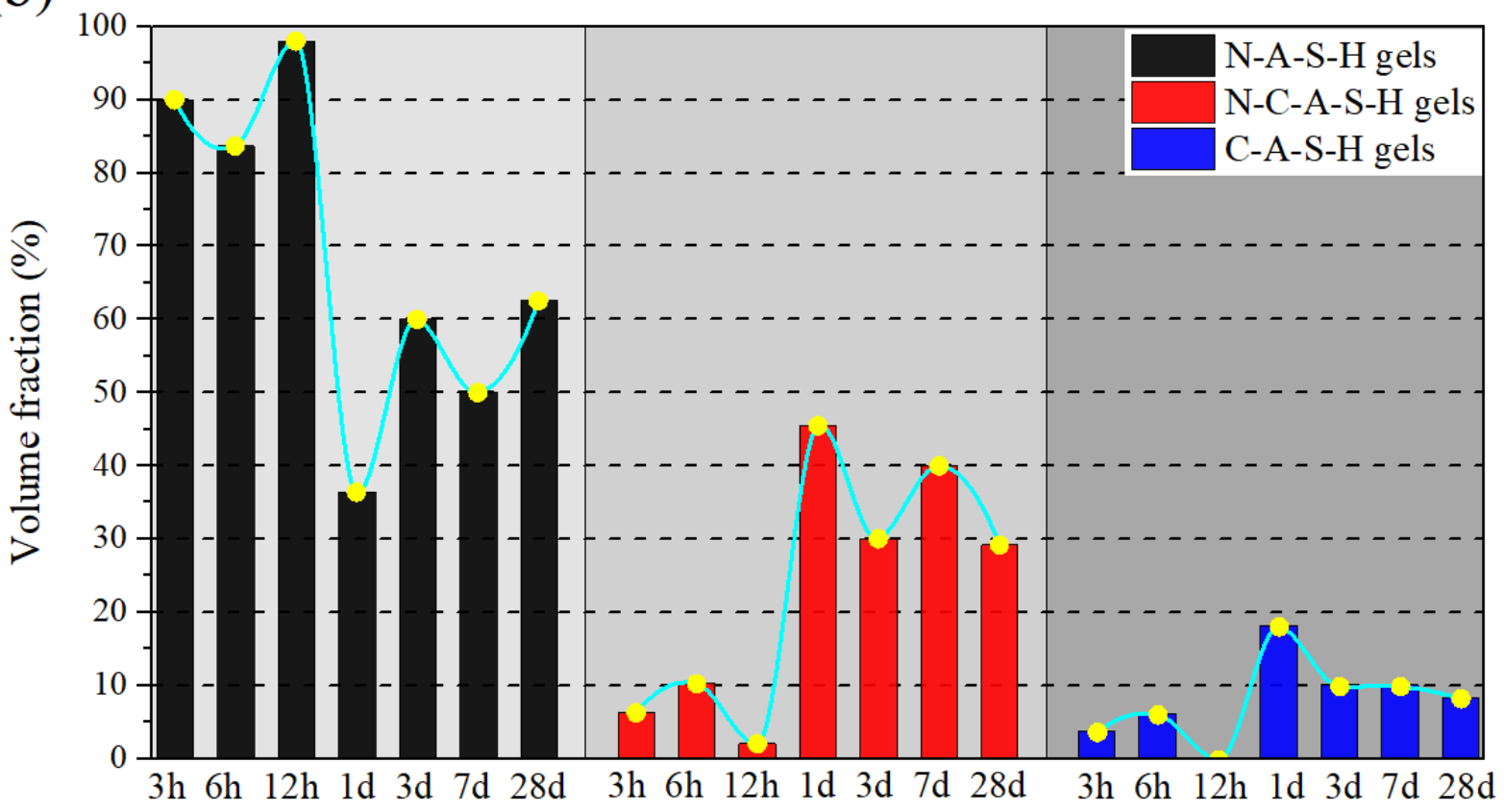

Fig. 10. Volume fraction of reaction products in ITZ (a) and paste matrix (b) of AAFS concrete at different curing ages 
(a) Original BSEM image

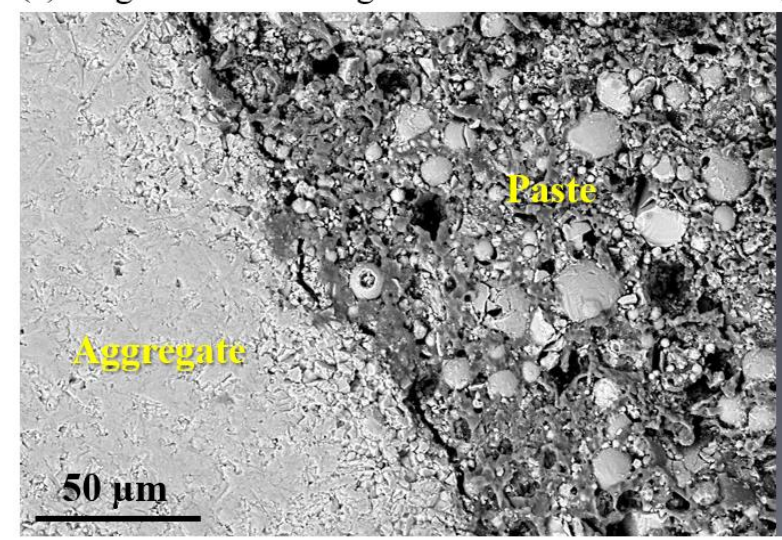

(c) Unreacted particles (b) Polychromatic BSEM image

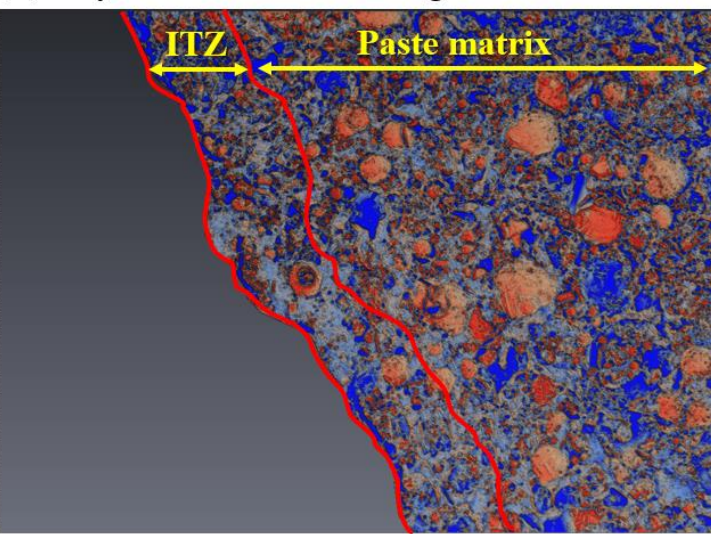

\section{Phase identification of gel composites \\ Unreacted particles \\ Reaction products \\ $\square$ Pores}

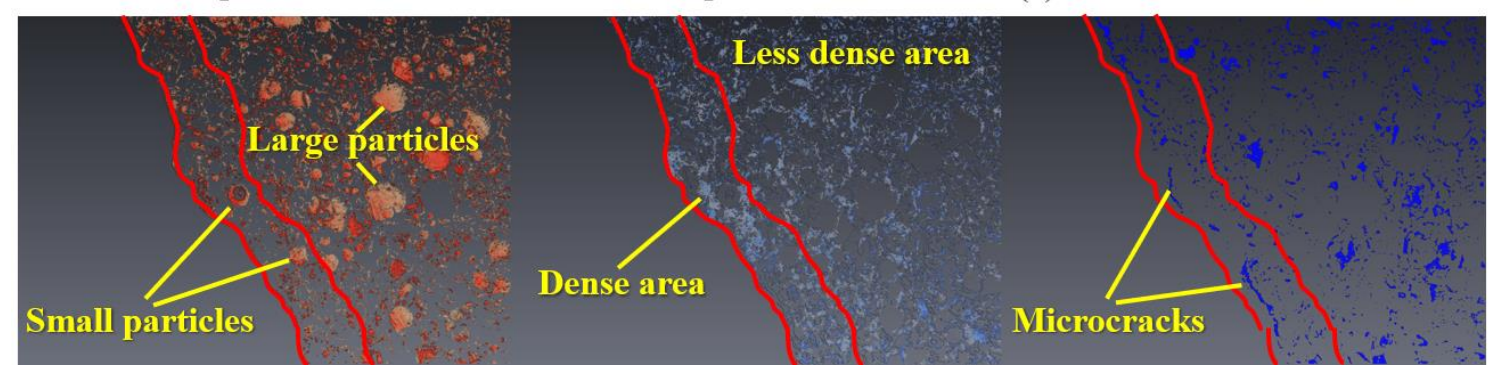

Fig. 11. Morphology of interface between aggregate and paste matrix of AAFS concrete $(\mathrm{t}=3 \mathrm{~h})$ 
(a)

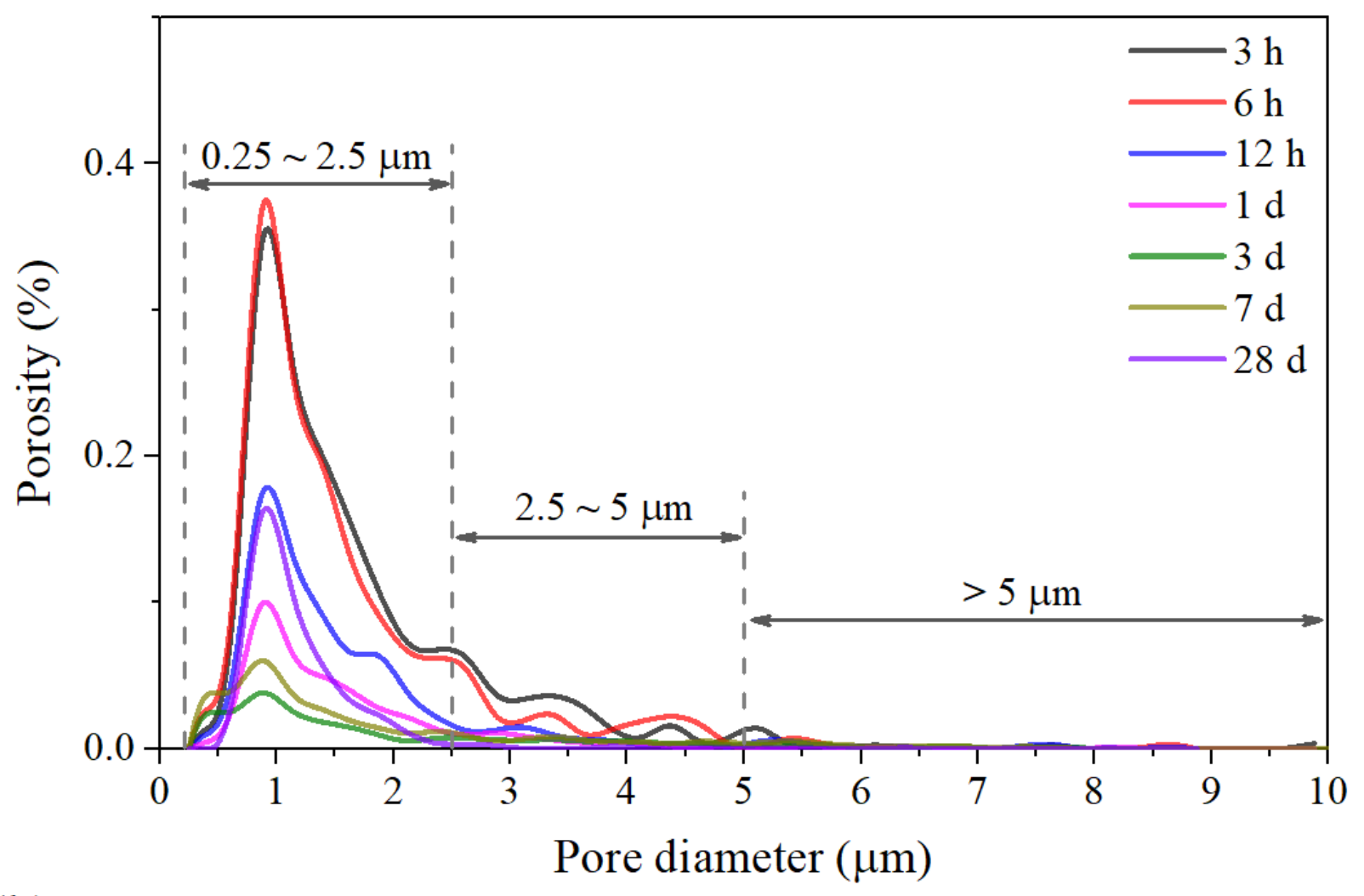

(b)

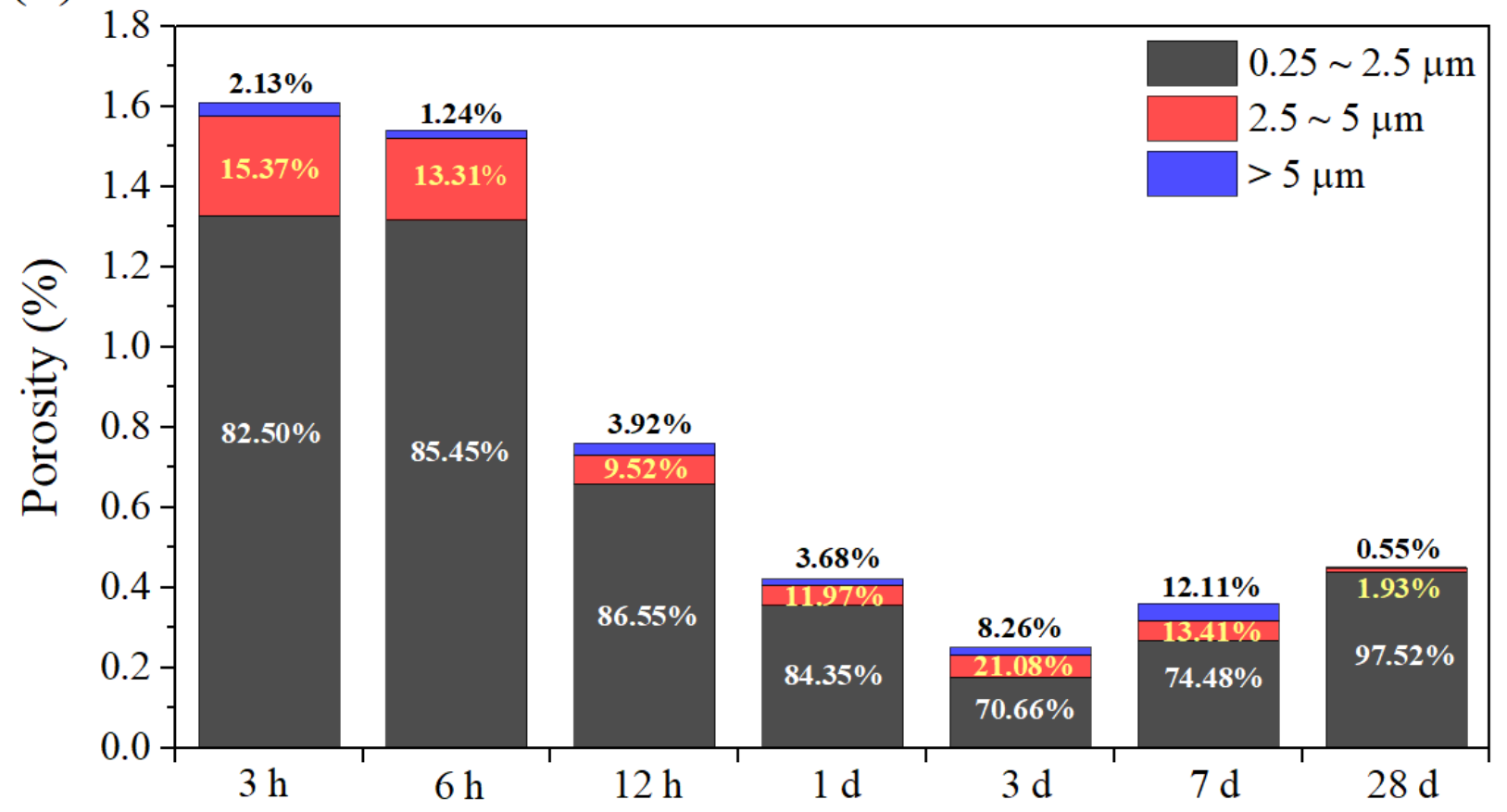

Fig. 12. Pore size distribution (a) and porosity fractions (b) in ITZ of AAFS concrete at different curing ages 
(a)

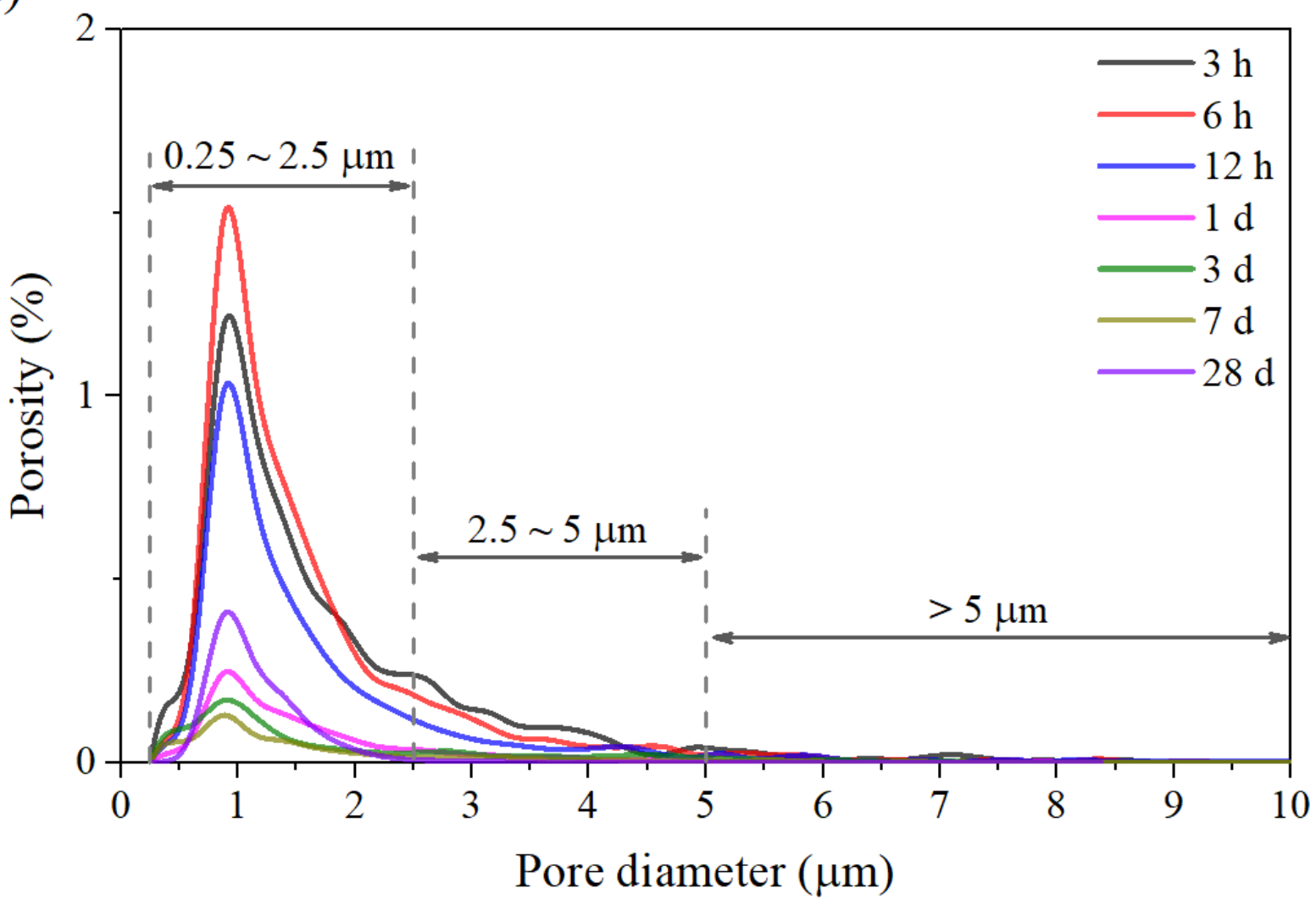

(b)

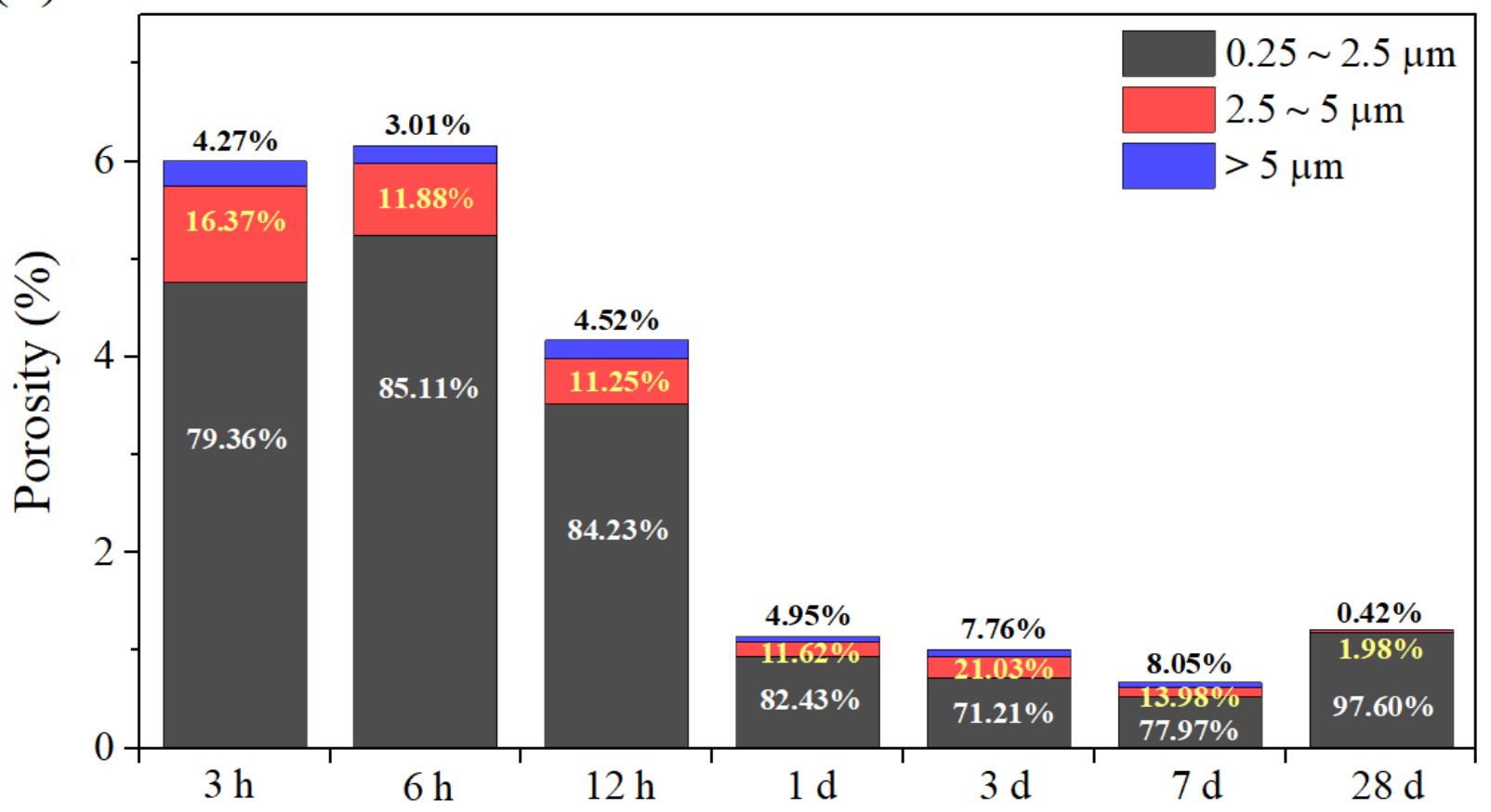

Fig. 13. Pore size distribution (a) and porosity fractions (b) in paste matrix of AAFS concrete at different curing ages 
(a) $3 \mathrm{~h}$

(b) $6 \mathrm{~h}$

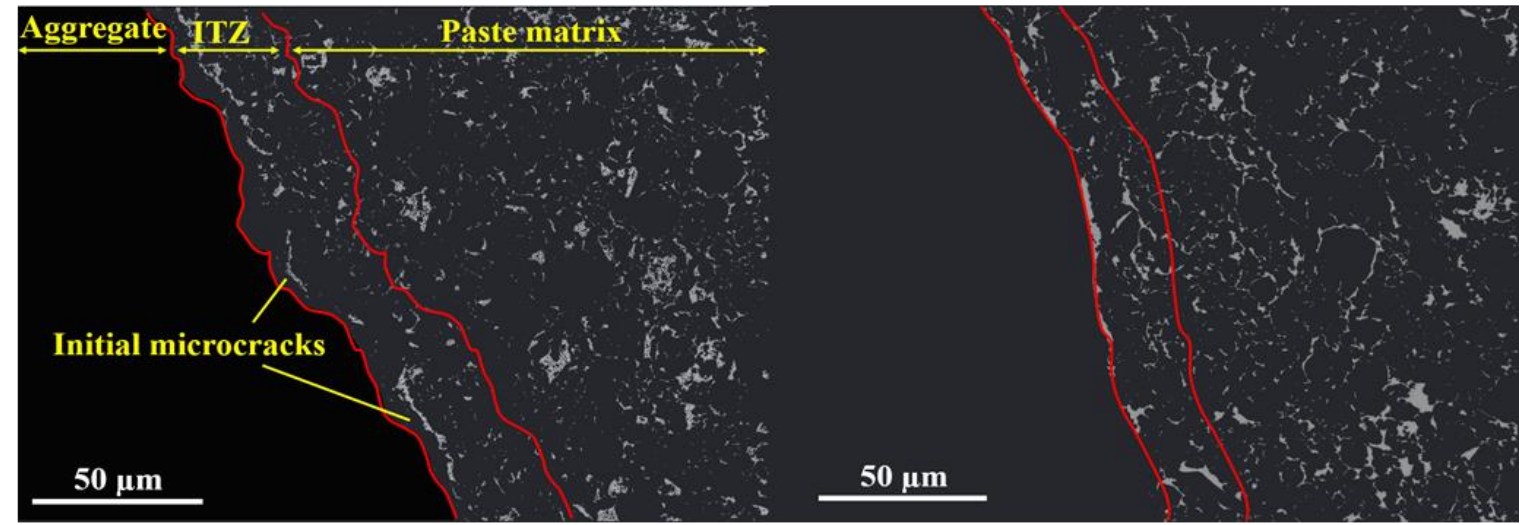

(c) $12 \mathrm{~h}$

(d) $1 \mathrm{~d}$

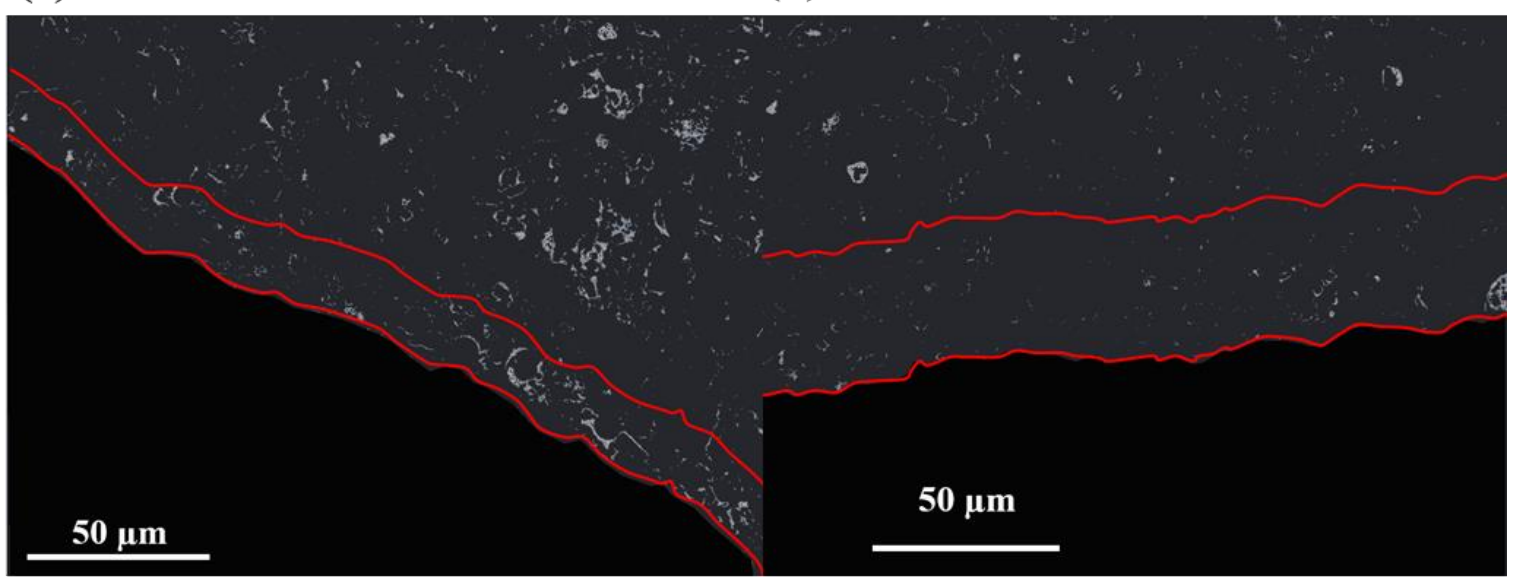

(e) $3 \mathrm{~d}$

(f) $7 \mathrm{~d}$

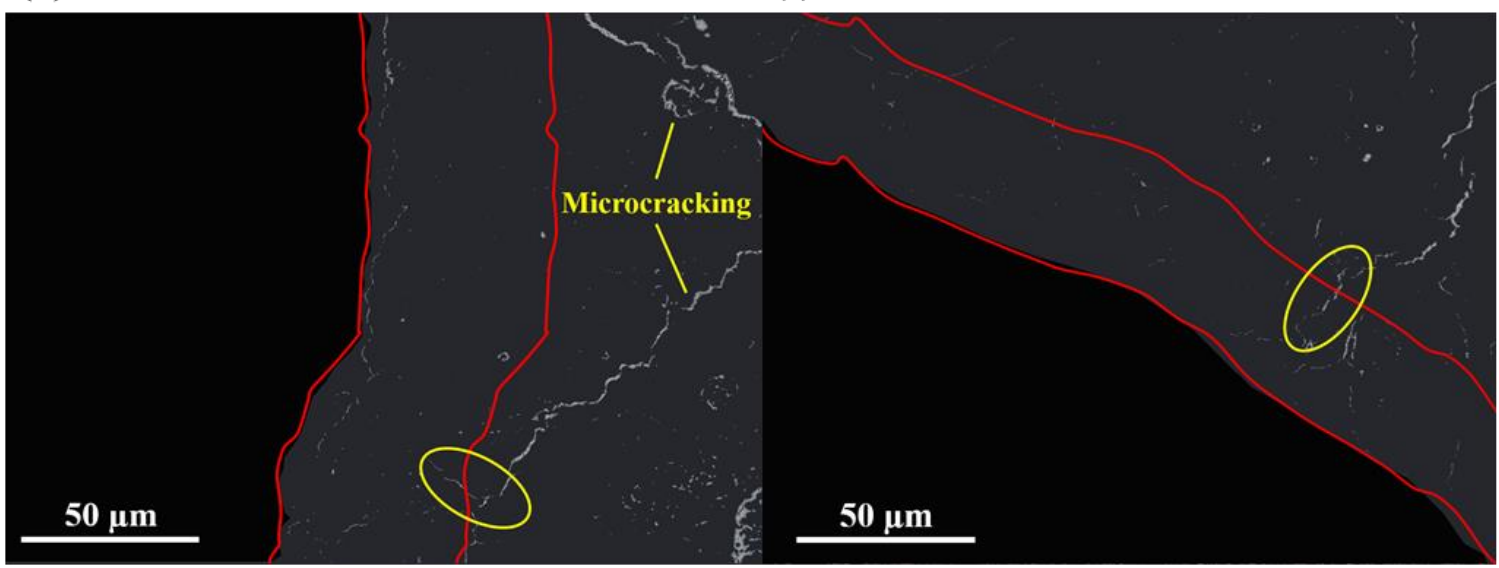

\section{(g) $28 \mathrm{~d}$}

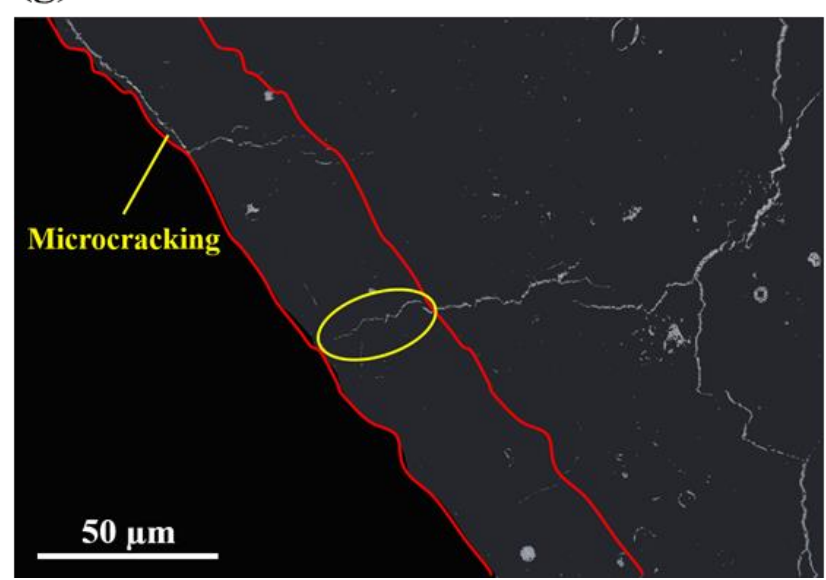

Fig. 14. Morphology of microcracks in ITZ and paste matrix of AAFS concrete at different curing ages 


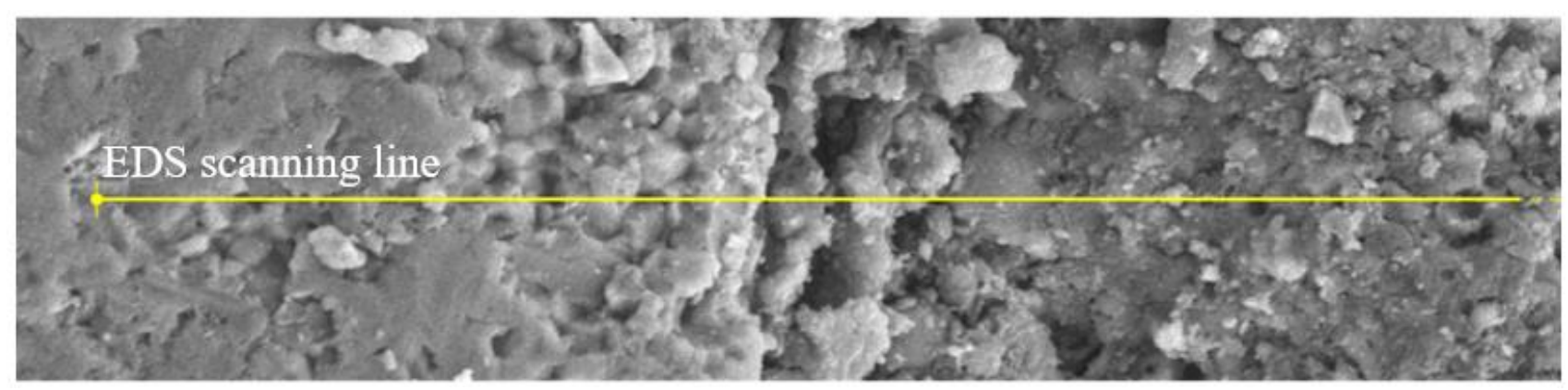

(a) $3 \mathrm{~h}$

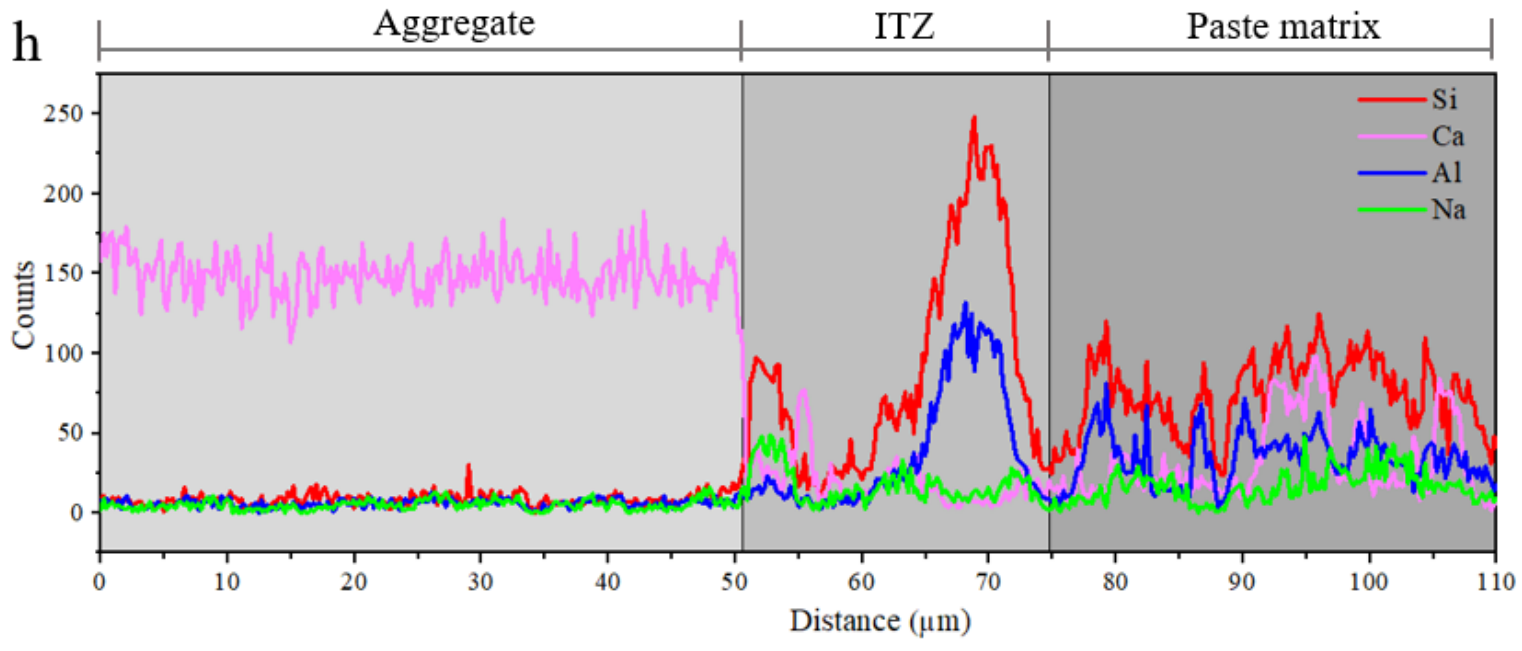

(b) $6 \mathrm{~h}$

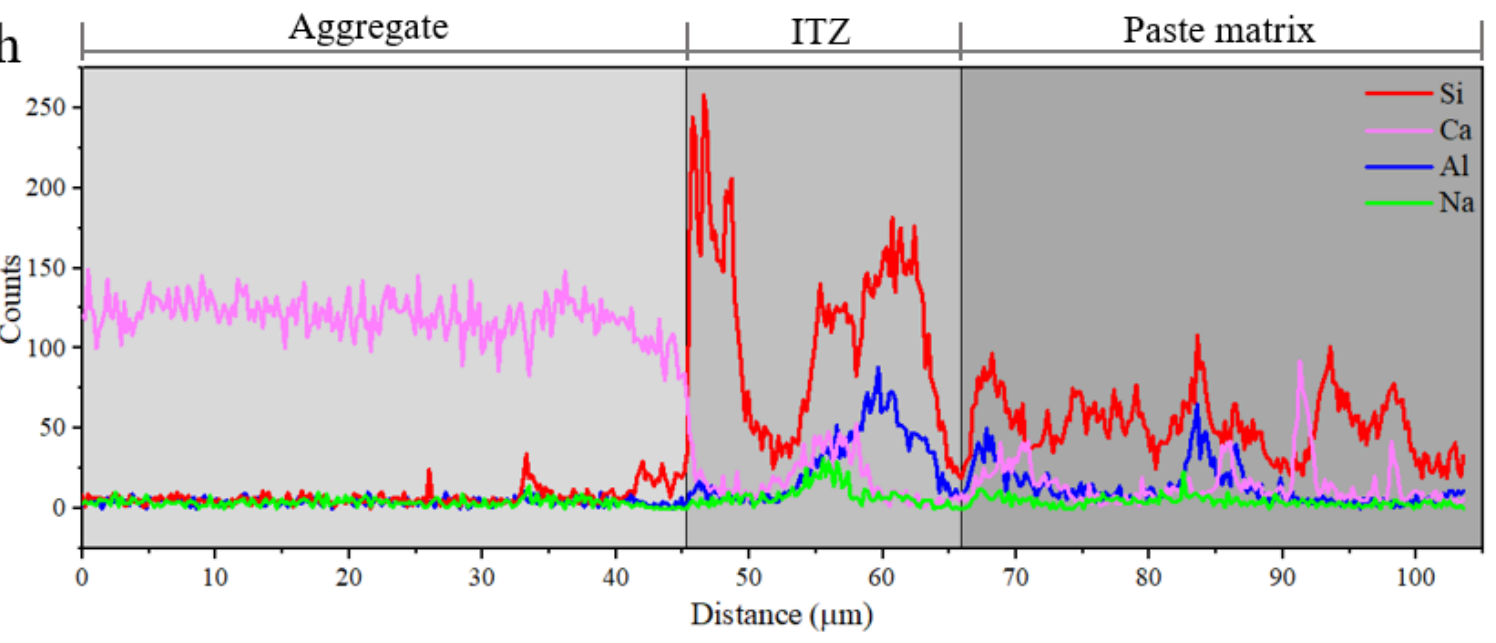

(c) $12 \mathrm{~h}$

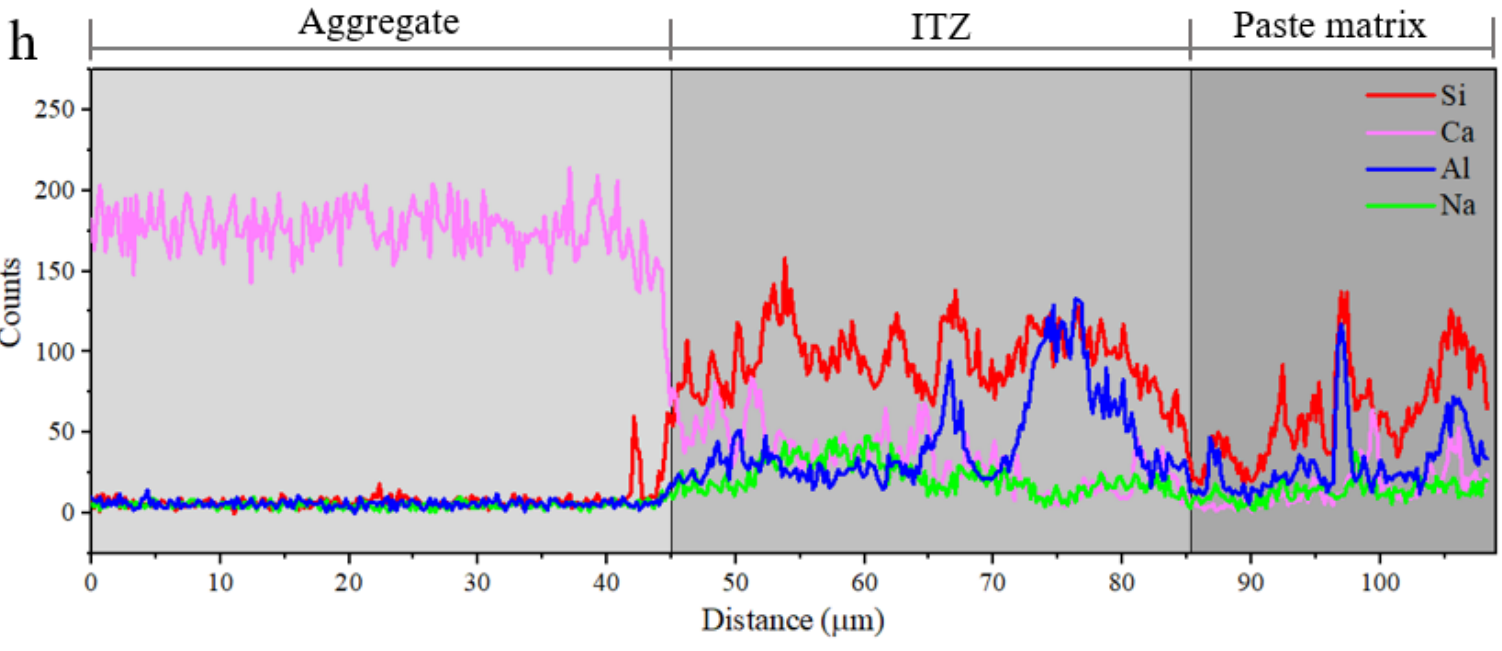


(d) $1 \mathrm{~d}$

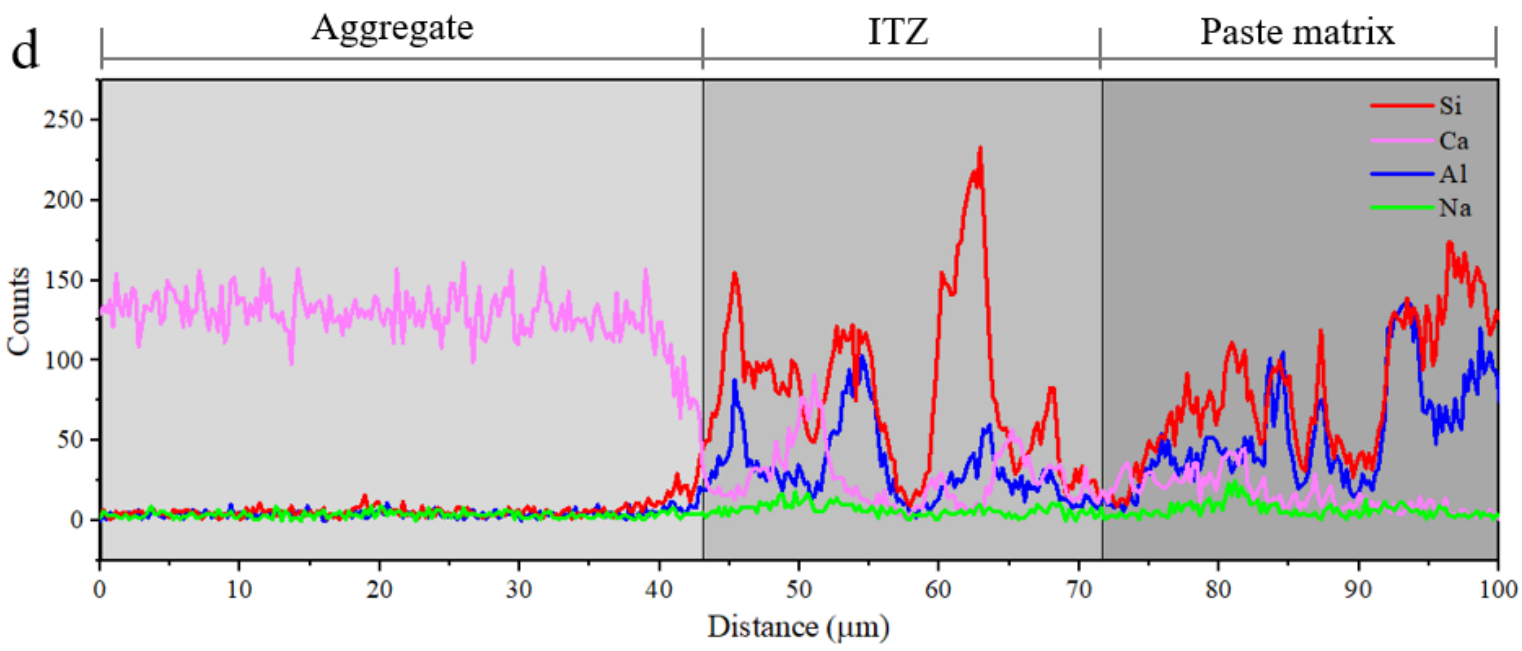

(e) $3 \mathrm{~d}$

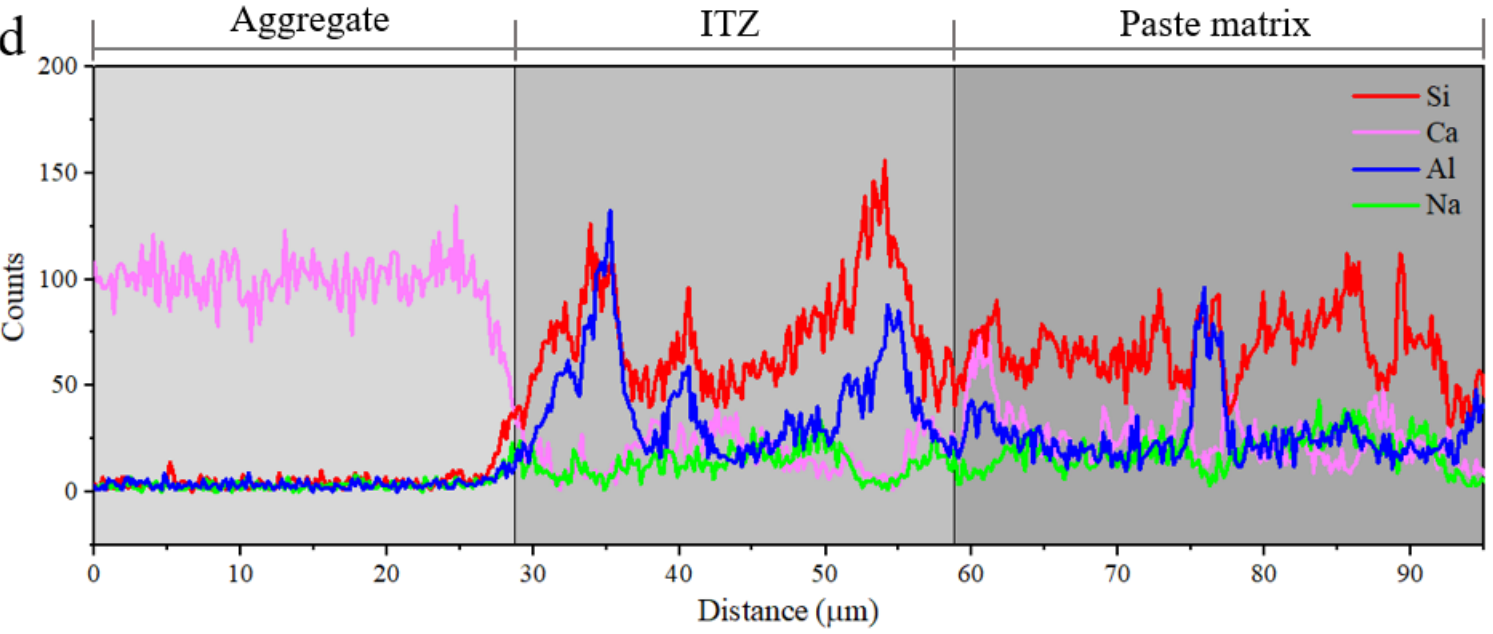

(f) $7 \mathrm{~d}$
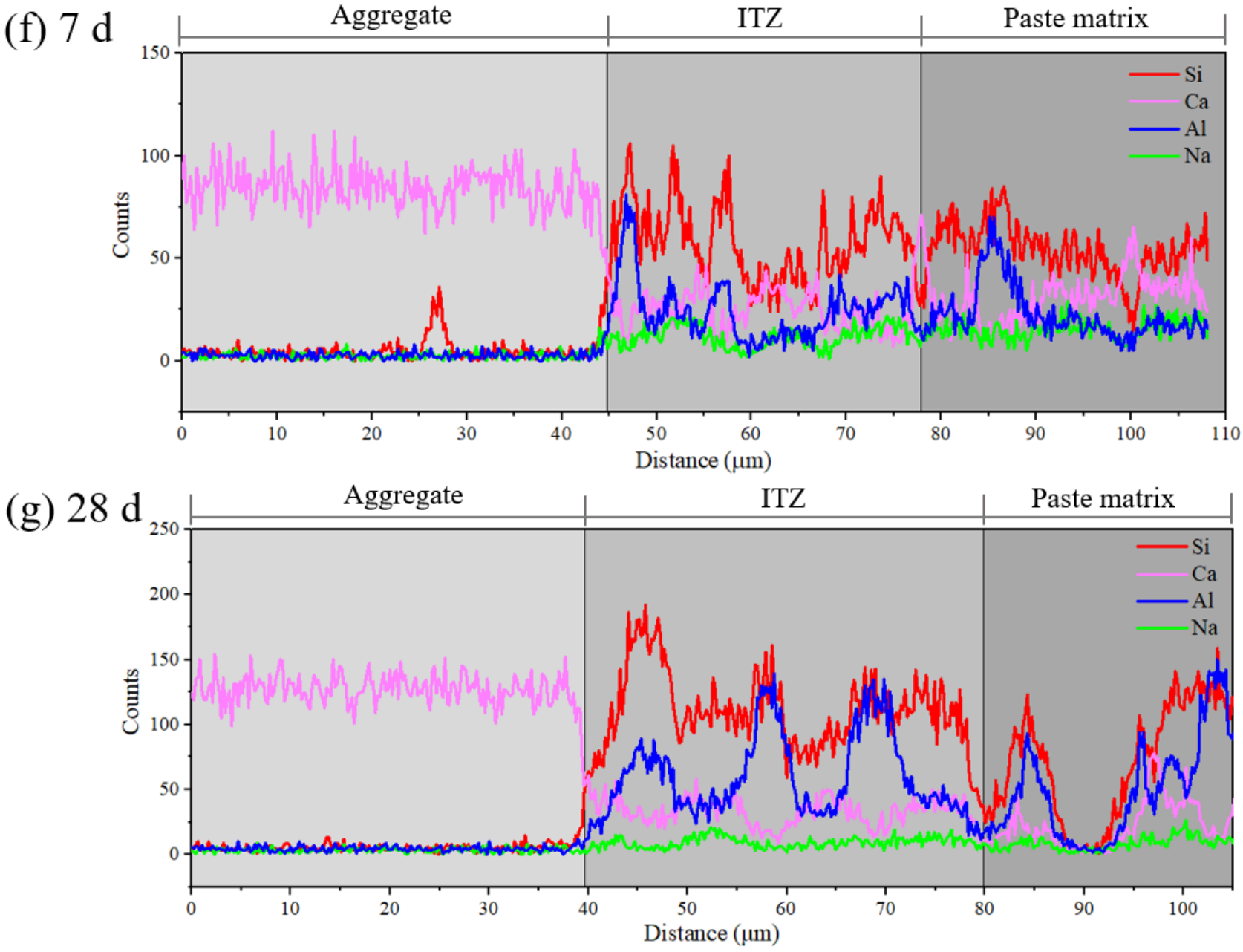

Fig. 15. Distribution of elements amount across the interface between aggregate and paste matrix of AAFS concrete at different curing ages 


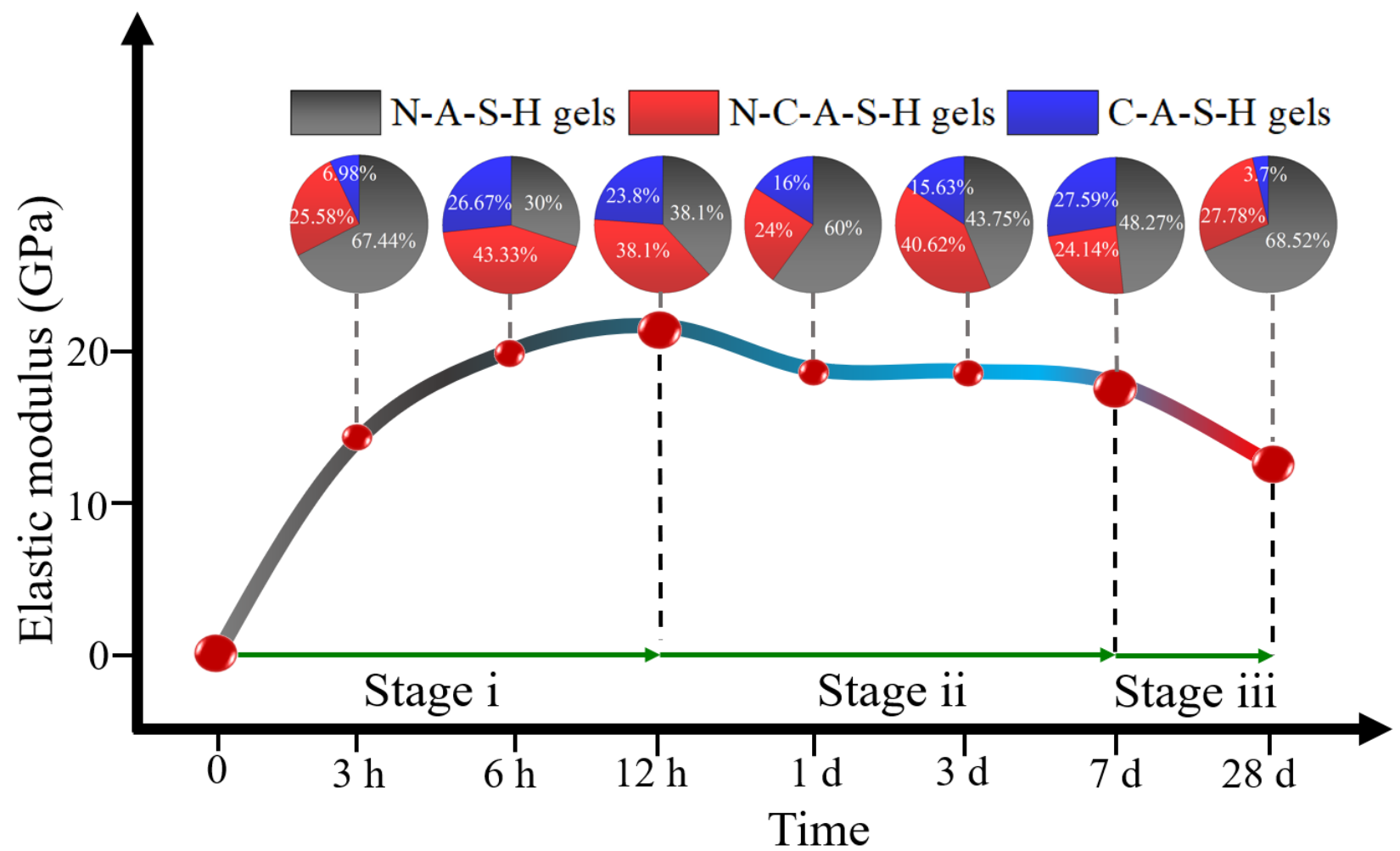

Fig. 16. Evolution of elastic modulus and volume fraction of reaction products in ITZ of AAFS concrete with curing age

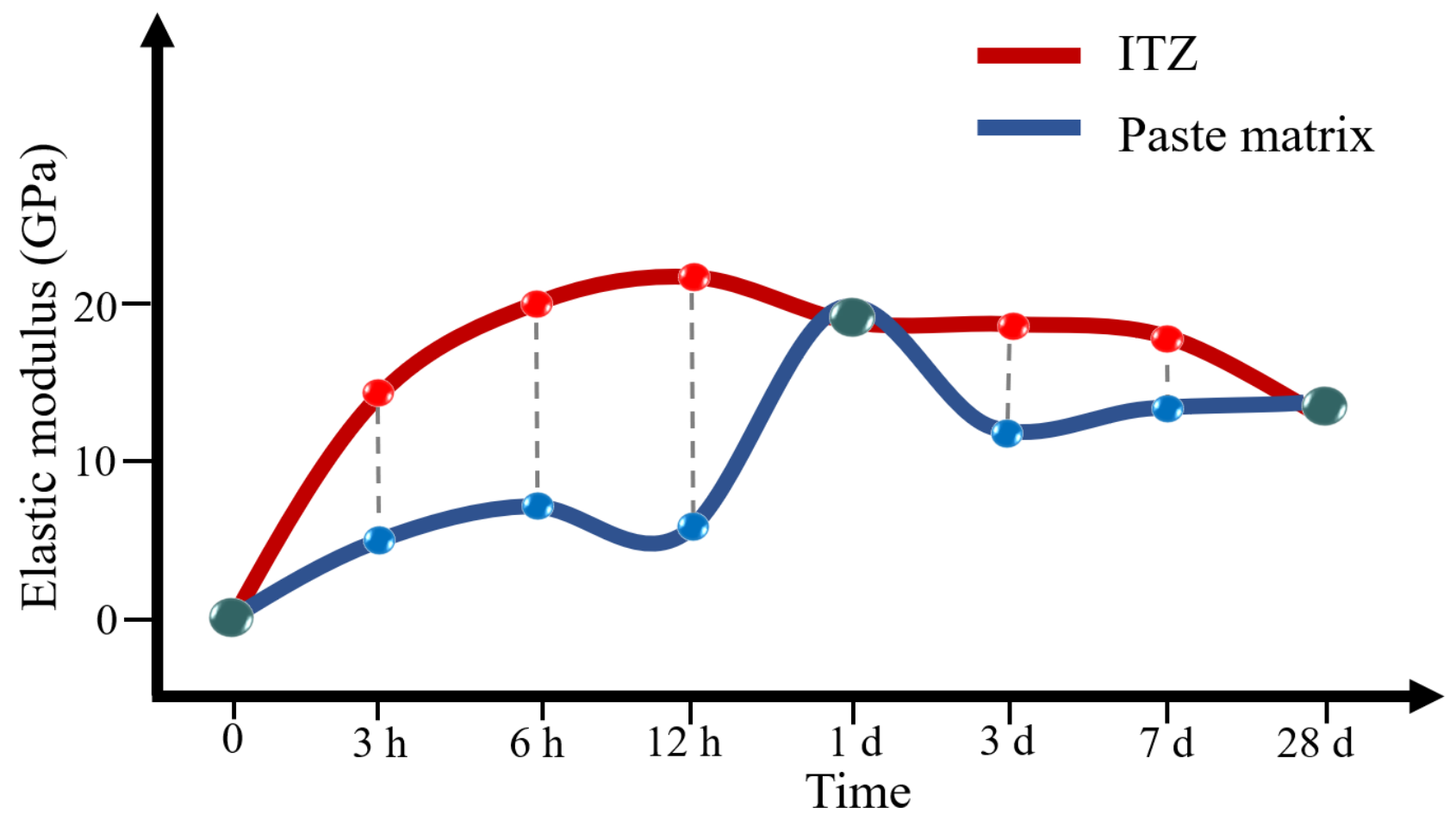

Fig. 17. Comparison between elastic moduli of ITZ and paste matrix of AAFS concrete at different curing ages 
Table 1. Chemical composition (wt $\%$ ) of FA and GGBS

\begin{tabular}{ccccccccccc}
\hline Oxide & $\mathrm{SiO}_{2}$ & $\mathrm{Al}_{2} \mathrm{O}_{3}$ & $\mathrm{Fe}_{2} \mathrm{O}_{3}$ & $\mathrm{CaO}$ & $\mathrm{K}_{2} \mathrm{O}$ & $\mathrm{MgO}$ & $\mathrm{TiO}_{2}$ & $\mathrm{Na}_{2} \mathrm{O}$ & $\mathrm{SO}_{3}$ & $\mathrm{P}_{2} \mathrm{O}_{5}$ \\
\hline FA & 55.76 & 30.22 & 3.56 & 2.33 & 0.91 & 0.46 & 1.72 & 0.40 & 0.79 & 0.27 \\
GGBS & 33.22 & 13.49 & 0.40 & 41.57 & 0.64 & 7.04 & 0.50 & 0.34 & 2.14 & - \\
\hline
\end{tabular}

Table 2. Specific density $\left(\mathrm{g} / \mathrm{cm}^{3}\right)$ of different ingredients in AAFS concrete

\begin{tabular}{cccccccc}
\hline & FA & GGBS & SS & SH & SP & Fine aggregate & Coase aggregate \\
\hline Specific density & 2.25 & 2.90 & 1.38 & 1.21 & 1.08 & 2.57 & 2.62 \\
\hline
\end{tabular}

Note: FA (fly ash); GGBS (ground granulated blast-furnace slag); SS (sodium silicate solution); SH (sodium hydroxide solution); SP (superplasticizer)

Table 3. Mixture quantity $\left(\mathrm{kg} / \mathrm{m}^{3}\right)$ of AAFS concrete

\begin{tabular}{cccccccc}
\hline & FA & GGBS & SS & SH & SP & Fine aggregate & Coase aggregate \\
\hline Mixture quantity & 300 & 100 & 120 & 60 & 4 & 622 & 1178 \\
\hline
\end{tabular}

Note: FA (fly ash); GGBS (ground granulated blast-furnace slag); SS (sodium silicate solution); SH (sodium hydroxide solution); SP (superplasticizer)

Table 4. RMS roughness (nm) of AAFS paste and concrete at different curing ages

\begin{tabular}{cccccccc}
\hline Curing age & $3 \mathrm{~h}$ & $6 \mathrm{~h}$ & $12 \mathrm{~h}$ & $1 \mathrm{~d}$ & $3 \mathrm{~d}$ & $7 \mathrm{~d}$ & $28 \mathrm{~d}$ \\
\hline Aggregate & 51 & 98 & 75 & 93 & 60 & 72 & 54 \\
\hline- ITZ $^{-0}$ & 132 & 106 & 122 & 124 & 103 & 97 & 138 \\
\hline
\end{tabular}

